\title{
Aspectos Florísticos da Estação Ecológica de Itapeva, SP: uma Unidade de Conservação no Limite Meridional do Bioma Cerrado
}

\author{
Roque Cielo-Filho ${ }^{1,5}$, Osny Tadeu de Aguiar², João Batista Baitello ${ }^{2}$, João Aurélio Pastore ${ }^{2}$, \\ Maria Teresa Zugliani Toniato ${ }^{3}$, Silvana Cristina Pereira Muniz de Souza2, \\ Conceição Rodrigues de Lima ${ }^{4}$, Renan Soares de Almeida ${ }^{2}$ \& Natalia de Oliveira Costa ${ }^{2}$ \\ ${ }^{1}$ Instituto Florestal, Floresta Estadual de Avaré, Rua Pernambuco, s/n, CEP 18701-180, Avaré, SP, Brasil \\ ${ }^{2}$ Instituto Florestal, Dasonomia, Rua do Horto, 931, CEP 02377-000, \\ São Paulo, SP, Brasil www.iflorestal.sp.gov.br \\ ${ }^{3}$ Instituto Florestal, Estação Experimental de Bauru, Av. Rodrigues Alves, 38-25, \\ CEP 17030-000, Bauru, SP, Brasil \\ ${ }^{4}$ Instituto Florestal, Estação Experimental de Tupi, Rod. Luiz de Queiroz, Km 149, \\ CEP 13428-000, Piracicaba, SP, Brasil \\ ${ }^{5}$ Autor para correspondência: Roque Cielo-Filho,e-mail: roque@if.sp.gov.br
}

CIELO-FILHO, R., AGUIAR, O.T., BAITELLO, J.B., PASTORE, J.A., TONIATO, M.T.Z., SOUZA, S.C.P.M, LIMA, C.R., ALMEIDA, R.S. \& COSTA, N.O. Floristic Aspects of the Itapeva Ecological Station, SP: a Protected Area in the Southern Limit of the Cerrado Biome. Biota Neotrop. 12(2): http://www.biotaneotropica. org.br/v12n2/en/abstract?inventory+bn00912022012

\begin{abstract}
The Itapeva Ecological Station - EEcI (24 04' S and 49 04' W, altitude 750 m), Itapeva, São Paulo State, is a Protected Area (PA) predominantly covered by cerrado denso and cerradão, whose occurrence in the region represents the southern limit of distribution of cerrado sensu lato. Aiming to know the regional flora and assuming the existence of floristic peculiarities due to the local weather conditions (incidence of frosts and absence of water deficit), we conducted a floristic survey in this PA from February 2008 to May 2010 and recorded 437 species in seven different physiognomies. In the cerrado sensu lato physiognomies, 346 species, distributed among 87 families and 220 genera, were found. The richest families were Asteraceae (31 species), Fabaceae (27), Myrtaceae (26), Melastomataceae (21), Rubiaceae (15), Lauraceae (12), Bignoniaceae (11) and Poaceae (10). Concerning richness and family representativeness, the EEcI flora does not differ from that of other cerrado sensu lato remnants at lower latitudes. However, frequent species in those remnants - Dimorphandra mollis, Xylopia aromatica, Eugenia aurata and Tocoyena formosa - were not found in the study area region, probably due to frost effects and other limiting climatic factors. On the other hand, geographical distribution models did not predict the occurrence of Annona dioica, Brosimum gaudichaudii, Duguetia furfuracea, Anadenanthera peregrina var. falcata, Caryocar brasiliense and Schefflera vinosa for the region of Itapeva, possibly due to the absence of water deficit. The floristic data obtained in this study may assist in the parameterization of these models. The floristic similarity observed between the physiognomic extremes of the cerrado sensu lato in the EEcI: cerradão and cerrado ralo, $26 \%$, was smaller than the floristic similarity between the swamp grassland physiognomy and the cerrado ralo (27\%), and between the former and the cerrado denso (30\%). Therefore, considering floristic composition as one of the defining aspects of vegetation type, the swamp grassland can be included in the delimitation of cerrado sensu lato in the EEcI. We recorded eight species threatened with extinction. Due to the PA's small dimensions, we suggest the expansion of its area for a more effective conservation of these species' populations.
\end{abstract}

Keywords: Cerrado concept, geographic distribution, Cerrado physiognomies, collecting effort, threatened species.

CIELO-FILHO, R., AGUIAR, O.T., BAITELLO, J.B., PASTORE, J.A., TONIATO, M.T.Z., SOUZA, S.C.P.M, LIMA, C.R., ALMEIDA, R.S. \& COSTA, N.O. Aspectos Florísticos da Estação Ecológica de Itapeva, SP: uma Unidade de Conservação no Limite Meridional do Bioma Cerrado. Biota Neotrop. 12(2): http://www. biotaneotropica.org.br/v12n2/pt/abstract?inventory+bn00912022012

Resumo: A Estação Ecológica de Itapeva - EEcI (24 04' S e 49 04' W, altitude 750 m), Itapeva, SP, é uma Unidade de Conservação (UC) de proteção integral com cobertura vegetal predominante de cerrado denso e cerradão, cuja ocorrência na região representa o limite meridional de distribuição do cerrado sensu lato. Buscando conhecer a flora regional e supondo a existência de particularidades florísticas devido às condições climáticas locais (ausência de déficit hídrico e incidência de geadas), realizamos um levantamento florístico nesta UC entre fevereiro de 2008 a maio de 2010 e registramos 437 espécies em sete diferentes fisionomias. Nas fisionomias de cerrado sensu lato foram encontradas 346 espécies distribuídas em 87 famílias e 220 gêneros. As famílias mais ricas foram Asteraceae (31 espécies), Fabaceae (27), Myrtaceae (26), Melastomataceae (21), Rubiaceae (15), Lauraceae (12), Bignoniaceae (11) e Poaceae (10). Em relação à riqueza e famílias mais representativas, a flora da EEcI não difere de outros remanescentes de cerrado sensu lato em latitudes mais baixas. Contudo, espécies frequentes 
naqueles remanescentes - Dimorphandra mollis, Xylopia aromatica, Eugenia aurata e Tocoyena formosa - não foram encontradas na região da área de estudo, provavelmente devido ao efeito de geadas e outros fatores climáticos limitantes. Por outro lado, Annona dioica, Brosimum gaudichaudii, Duguetia furfuracea, Anadenanthera peregrina var. falcata, Caryocar brasiliense e Schefflera vinosa não tinham ocorrência prevista na região de Itapeva por modelos de distribuição geográfica, possivelmente devido à ausência de déficit hídrico. As informações florísticas obtidas neste estudo poderão auxiliar na parametrização desses modelos. A similaridade florística observada entre os extremos fisionômicos de cerrado sensu lato de interflúvio na EEcI: cerradão e cerrado ralo, $26 \%$, foi menor do que a similaridade florística entre a fisionomia campestre úmida e o cerrado ralo (27\%), e entre a primeira e o cerrado denso (30\%). Portanto, considerando a composição florística como um dos aspectos definidores do tipo de vegetação, a fisionomia campestre úmida pode ser incluída na delimitação de cerrado sensu lato na EEcI. Foram registradas oito espécies ameaçadas de extinção. Devido às dimensões reduzidas da UC, sugerimos a sua ampliação visando maior efetividade na conservação das populações dessas espécies.

Palavras-chave: conceito de Cerrado, distribuição geográfica, fisionomias de Cerrado, esforço de coleta, espécies ameaçadas.

\section{Introdução}

O Cerrado pode ser considerado como um bioma de savana, uma grande área geográfica marcada por um ambiente relativamente uniforme e pela predominância das fitofisionomias savânicas campo sujo, campo cerrado e cerrado sensu stricto (Coutinho 2006). Acrescidas das fisionomias florestal e campestre, cerradão e campo limpo, aquelas fisionomias constituem, segundo o conceito floresta-ecótono-campo de Coutinho (1978), o cerrado sensu lato (s.l.), ou simplesmente Cerrado, termo utilizado para designar tanto o Bioma quanto o tipo de vegetação que o caracteriza (Coutinho 2002, 2006). Diferentemente de Coutinho (2006), Ribeiro \& Walter (2008) não restringem o bioma Cerrado ao cerrado (s.l.), mas incluem outras fisionomias florestais e savânicas que ocorrem na região. Além disso, na delimitação de cerrado (s.l.), aqueles autores admitem três subtipos para os campos sujo e limpo: úmido, seco e com murundus (Ribeiro \& Walter 2008). Neste trabalho, usaremos o termo Cerrado para nos referir ao Bioma conforme definido acima, com base em Coutinho (2006), mas admitiremos a existência de variantes úmidas para os campos sujo e limpo, com base em Ribeiro \& Walter (2008). O Cerrado também pode ser considerado como um conjunto de biomas (Coutinho 2002, Ribeiro \& Walter 2008, Batalha 2011), contudo, o conceito de bioma de savana é amplamente aceito na literatura nacional e internacional (Coutinho 2006) e sob tal conceituação, o mapeamento do Cerrado, em conjunto com outros biomas nacionais, torna-se mais simples.

A inclusão das fisionomias campestres úmidas constitui a principal diferença entre a delimitação de cerrado (s.l.) proposta por Ribeiro \& Walter (2008) e aquela sugerida por Coutinho (1978). Este autor entende o cerrado (s.l.) como vegetação de interflúvio, sobre solo bem drenado, mesma acepção encontrada em Oliveira-Filho $\&$ Ratter (2002). Almeida et al. (2010) consideraram o campo sujo úmido da Estação Ecológica de Itapeva (EEcI) como fisionomia de cerrado (s.l.) admitindo que a composição florística constitui um dos aspectos que podem ser considerados na delimitação do tipo de vegetação, juntamente com a fisionomia e as condições ecológicas (Eiten 1979, Rizzini 1997). No entanto, Almeida et al. (2010) não avaliaram formalmente as relações florísticas entre as diferentes fitofisionomias da EEcI. A análise dessas relações envolvendo a fisionomia campestre úmida (campos limpo e sujo úmidos) e as fisionomias de cerrado (s.l.) sobre solos bem drenados pode auxiliar na delimitação do cerrado (s.l.) na área de estudo.

Segundo Coutinho (2002), a área de abrangência do Cerrado compreende entre 1,8 a 2 milhões de $\mathrm{km}^{2}$. Tem como área core o Planalto Central, estendendo-se em seu limite meridional de distribuição, até o estado do Paraná (Brasil 2008a). Na história recente da ocupação do território nacional, foi o Bioma que mais cedeu espaço para a implantação de áreas destinadas a atividades agrícolas, silviculturais, pecuárias e para a urbanização (Klink \& Machado 2005). Em São Paulo, entre 1962 e 2001, a área ocupada por cerrado (s.l.) foi reduzida em $88,5 \%$ de sua extensão (Kronka et al. 2005). A importância biológica do Cerrado vem sendo enfatizada recentemente (Mittermeier et al. 1999, Aguiar \& Camargo 2004, Klink \& Machado 2005, Sano et al. 2008), e embora seja considerável o número de espécies ameaçadas de extinção no Bioma (São Paulo 2004, Fundação Biodiversitas 2008), o percentual de sua área ocupada por unidades de conservação (UC) de proteção integral é de apenas 2,48\% (Arruda et al. 2008).

A EEcI é uma dessas unidades, localizada no limite meridional de distribuição do Cerrado. Tal localização acentua a importância da UC como área protegida devido a possíveis peculiaridades florísticas inerentes a condições climáticas diferentes daquelas que predominam na área core do Bioma. Ratter et al. (2003), considerando apenas espécies lenhosas de cerrado (s.l.), reconheceram cinco províncias florísticas, sendo que uma delas abrange remanescentes situados no estado de São Paulo. Por outro lado, considerando apenas os remanescentes paulistas, verificou-se uma diferenciação na flora lenhosa entre áreas situadas ao norte e ao sul do Estado (Durigan et al. 2003). Essas diferenças estariam relacionadas a variações climáticas, especialmente a duração do período seco e a temperatura, resultando em diferenciações florísticas dentro de um mesmo tipo fisionômico (Durigan et al. 2003).

De acordo com Leitão-Filho (1992), no estado de São Paulo existiria um gradiente latitudinal na flora arbórea do cerrado (s.l.), sendo os remanescentes do sul desprovidos de algumas espécies encontradas nos remanescentes do norte, provavelmente devido a geadas que atuariam como fator restritivo à ocorrência dessas espécies. A ausência de algumas espécies típicas de cerrado foi relatada para áreas no Paraná, sugerindo que este Estado constituiria o limite meridional de distribuição dessas espécies (Linsingen et al. 2006, Ritter et al. 2010). Contudo, considerando o gradiente latitudinal, é possível que tal limite ocorra no estado de São Paulo, o que pode ser aferido por meio do estudo da flora de remanescentes de cerrado (s.l.) no extremo meridional de distribuição do Bioma no Estado. Tais estudos são ainda escassos (Scaramuzza 2006), assim, o estudo florístico da EEcI pode ajudar a preencher essa lacuna e auxiliar no reconhecimento dos limites meridionais de distribuição geográfica de espécies de cerrado (s.l.).

Adicionalmente, a disponibilidade de dados florísticos contribui para aumentar a precisão de modelos de distribuição geográfica 
dos taxons, que podem ser úteis como ferramentas de apoio ao planejamento de ações de conservação da biodiversidade (Peterson 2001, Stockwell \& Peterson 2002). Em revisão recente sobre o tema, Feeley \& Silman (2011) consideraram que a coleta de novos espécimes é fundamental para o desenvolvimento de modelos que possam prever acuradamente a distribuição das espécies de plantas tropicais e as possíveis alterações na distribuição geográfica dessas espécies frente às mudanças climáticas globais. Assim, a inclusão de estudos florísticos realizados na região climática da área de estudo poderia ajudar a melhorar os modelos de distribuição geográfica de espécies de cerrado (s.l.) no estado de São Paulo (Siqueira \& Durigan 2007). É possível abordar essa questão indiretamente por meio da comparação entre as previsões de incidência de espécies dos modelos e os dados obtidos no presente trabalho.

O objetivo geral deste estudo foi caracterizar a flora vascular da Estação Ecológica de Itapeva, especialmente a flora de cerrado (s.l.). Os objetivos específicos foram: (a) avaliar se a fisionomia campestre úmida da Estação pode ser incluída no tipo de vegetação cerrado (s.l.), considerando a composição florística; (b) identificar espécies ameaçadas de extinção na Unidade; (c) verificar se a região da área de estudo representa o limite meridional de distribuição de espécies lenhosas típicas de cerrado (s.l.); e (d) comparar os dados de incidência de espécies obtidos a partir do levantamento florístico com a incidência prevista por modelos de distribuição geográfica no estado de São Paulo.

\section{Material e Métodos}

\section{Localização, clima, relevo, solo e tipos de vegetação}

A Estação Ecológica de Itapeva, criada pelo Decreto Estadual $n^{\circ} 7.692 / 76$, está situada no município de Itapeva, na região sudoeste do estado de São Paulo, na microbacia do rio Pirituba, bacia do Alto Paranapanema (24 04' S e 49 $04^{\prime}$ W, altitude $750 \mathrm{~m}$ ). A EEcI possui 107 ha, sendo delimitada ao norte pela Rodovia Francisco Alves Negrão (SP 258); ao sul, pelo assentamento rural Pirituba II área IV; a leste, pelo rio Pirituba e, a oeste, pelo córrego do Banhado. Encontrase em região caracterizada por colinas de topos convexos com declives de 10 a 20\%, na Depressão Periférica Paulista, zona do Paranapanema (Ross \& Moroz 1997). O clima na região é classificado como Cfb na classificação de Koeppen, com 18 a $20{ }^{\circ} \mathrm{C}$ de temperatura média anual, variando de 26 a $28^{\circ} \mathrm{C}$ a temperatura média do mês de janeiro, e de 8 a $16^{\circ} \mathrm{C}$ a média do mês de julho. A precipitação anual varia entre 1.200 a $1.400 \mathrm{~mm}$ (Instituto de Pesquisas Tecnológicas 2001).

$\mathrm{Na}$ EEcI predominam o Latossolo Vermelho Amarelo e o Argissolo Amarelo, mas ocorrem também associações de Argissolo Amarelo + Neossolo Litólico e Gleissolo Melânico + Gleissolo Háplico (Novais et al. 2009). Possui 100,42 ha de vegetação natural, distribuídos em sete categorias fisionômicas (Cielo-Filho et al. 2011). As categorias de cerrado (s.l.) foram definidas de acordo com o sistema de classificação de Ribeiro \& Walter (2008), incluindo campo limpo e sujo úmidos (2,44 ha), cerrado ralo ( $3,10 \mathrm{ha})$, cerrado denso (42,88 ha) e cerradão (44,15 ha). Utilizamos o sistema de Veloso et al. (1991) para classificar as fisionomias extra cerrado (s.l.), que na EEcI consistem de Floresta Estacional Semidecidual Montana (6,92 ha) e Floresta Estacional Semidecidual Aluvial (0,93 ha). Assim, dois biomas estão representados na Estação por fisionomias pertencentes aos seus respectivos tipos de vegetação sentido amplo: o Cerrado (Coutinho 2006) e a Mata Atlântica (Oliveira-Filho \& Fontes 2000).

\section{Amostragem florística e análise de dados}

Todas as categorias fisionômicas e formas de vida de plantas vasculares foram consideradas na amostragem florística. No entanto, por predominarem na área, as fisionomias de cerrado (s.l.) receberam maior ênfase no detalhamento dos resultados e na discussão. A listagem florística do campo sujo úmido foi publicada em trabalho à parte (Almeida et al. 2010) e não é apresentada aqui. Contudo, os dados referentes ao número de espécies, espécies ameaçadas e distribuição de riqueza entre hábitos e famílias naquela fisionomia também foram considerados para compor os valores totais dessas variáveis para o cerrado (s.l.).

O método adotado teve como base o caminhamento (Filgueiras et al. 1994). Foram percorridas as trilhas existentes e as abertas para a elaboração deste trabalho, bem como as bordas da Estação em seus limites norte e sul, no período compreendido entre os meses de fevereiro de 2008 e maio de 2010. As visitas a campo tiveram duração de três dias e periodicidade mensal. A coleta e a herborização do material botânico seguiram as recomendações de Fidalgo \& Bononi (1989). A identificação de materiais férteis e estéreis foi feita por meio de comparação com exsicatas depositadas nos herbários Dom Bento Pickel (SPSF) e Maria Eneyda P. K. Fidalgo (SP) e de consulta à bibliografia e a especialistas.

Materiais férteis foram tombados e depositados no Herbário SPSF e os respectivos registros estão disponíveis para consulta online (Species Link 2010). As espécies foram ordenadas em gêneros e famílias de acordo com o sistema APG III (Judd et al. 2002, Souza \& Lorenzi 2008, Angiosperm Phylogeny Group 2009). Para verificação de sinonímias botânicas e grafias foram consultados os bancos de dados W3 Tropicos (Missouri Botanical Garden 2010), International Plant Names Index (International Plant Names Index 2010) e Lista de Espécies da Flora do Brasil (Jardim Botânico do Rio de Janeiro 2010). Na lista de espécies foram indicados o nome popular, o hábito, a fisionomia em que a espécie foi coletada e o número de tombo SPSF. Devido às pequenas dimensões da Estação, não foram apresentadas as coordenadas geográficas para as coletas individuais, mas essas coordenadas podem ser obtidas no sistema de busca do Species Link escolhendo a coleção SPSF e utilizando o número de tombo como filtro.

Para avaliar se a fisionomia campestre úmida da EEcI pode ser considerada como cerrado (s.l.), as espécies do campo sujo úmido (Almeida et al. 2010) e campo limpo úmido foram agrupadas em uma única lista para representar a fisionomia campestre úmida. Esta lista foi comparada, considerando apenas o estrato herbáceo-arbustivo, com a lista geral das fisionomias de cerrado (s.l.) de interflúvio, que na EEcI inclui cerradão, cerrado denso e cerrado ralo, e com a lista da Floresta Estacional Semidecidual Montana. Devido à área relativamente pequena ocupada pela Floresta Estacional Semidecidual Montana, adicionamos à respectiva lista as espécies do mesmo estrato e fisionomia encontradas na Estação Experimental de Itapeva, que é contígua à EEcI (Souza et al. in prep.). As comparações foram feitas por meio do índice de similaridade de Sorensen (Legendre \& Legendre 1998). Também comparamos, por meio do mesmo índice, mas considerando todos os estratos, cada uma das listas individuais das fisionomias de cerrado (s.l.) de interflúvio entre si e com a lista da fisionomia campestre úmida. Assumimos que a delimitação de cerrado (s.l.) deveria incluir a fisionomia campestre úmida se: (1) a similaridade entre a lista dessa fisionomia fosse maior em relação à lista geral de cerrado (s.l.) do que em relação à lista da Floresta Estacional Semidecidual Montana; e (2) as similaridades obtidas nas comparações das listas individuais das fisionomias que compõem o cerrado (s.l.) de interflúvio entre si fossem comparáveis às similaridades obtidas nas comparações entre aquelas listas e a lista da fisionomia campestre úmida.

Consultamos as seguintes fontes para verificação do nível de ameaça de extinção das espécies encontradas: 
Lista Oficial de Espécies Ameaçadas de Extinção no Estado de São Paulo - SMA-SP (São Paulo 2004);

Revisão da Lista de Espécies da Flora Brasileira Ameaçada de Extinção - FB (Fundação Biodiversitas 2008);

Lista Oficial das Espécies da Flora Brasileira Ameaçadas de Extinção - MMA (Brasil 2008b);

Lista Vermelha de Espécies Ameaçadas de Extinção da União Internacional para a Conservação da Natureza - IUCN (International Union for Conservation of Nature 2010).

A lista da Fundação Biodiversitas foi utilizada, juntamente com a lista do Ministério do Meio Ambiente, para a análise das espécies ameaçadas em escala nacional, por ser mais abrangente do que esta última. Como a lista MMA não apresenta as categorias de ameaça das espécies, os resultados obtidos a partir dessa lista são apenas de presença ou ausência, indicadas pelos números 1 ou 0 , respectivamente. As categorias de ameaça adotadas nas listas SMA-SP e FB são baseadas nas categorias adotadas na lista IUCN, as quais apresentam a seguinte ordenação de acordo com o grau decrescente de ameaça (International Union for Conservation of Nature 2001): Extinta (EX), Extinta na Natureza (EW), Criticamente Ameaçada (CR), Ameaçada (EN), Vulnerável (VU), Baixo Risco (LR). Informações sobre os tipos de ameaça foram obtidas em Souza et al. (2007) e nos sítios eletrônicos da Fundação Biodiversitas (Fundação Biodiversitas 2008) e da União Internacional para a Conservação da Natureza - IUCN (International Union for Conservation of Nature 2010).

Para verificar se a região da área de estudo representa o limite meridional de distribuição geográfica para espécies arbóreas típicas do cerrado (s.l.) utilizamos dois conjuntos de espécies como parâmetro. $\mathrm{O}$ primeiro envolve as 25 espécies consideradas frequentes (frequência superior a $70 \%$ ) na província florística do extremo sul do Bioma (Bridgewater et al. 2004), que inclui predominantemente remanescentes de Cerrado paulistas (Ratter et al. 2003). O segundo grupo abrange as 17 espécies mais frequentes em remanescentes de Cerrado paulistas apontadas por Siqueira \& Durigan (2007). Na análise destas autoras não foram incluídos levantamentos florísticos em latitudes semelhantes ou superiores à da EEcI e, em Ratter et al. (2003), apenas uma das áreas incluídas nas comparações situa-se em posição mais meridional do que a EEcI. Assim, consideramos que a ausência na EEcI de espécies dos dois conjuntos mencionados acima pode indicar o limite meridional de distribuição para essas espécies.

A comparação dos dados de incidência de espécies obtidos a partir do levantamento florístico com a incidência prevista por modelos de distribuição geográfica no estado de São Paulo considerou os modelos gerados por algoritmo genético apresentados em Siqueira \& Durigan (2007). Esses modelos foram gerados a partir de um conjunto de levantamentos florísticos de áreas situadas em latitudes mais baixas do que a da EEcI e foram usados para prever a distribuição do bioma Cerrado bem como de algumas de suas espécies mais importantes no estado de São Paulo.

\section{Resultados}

A lista florística apresentada aqui (Tabela 1) totalizou 399 espécies de plantas vasculares, sendo que 99 foram identificadas por meio do exame de material vegetativo, pois não foram coletadas em período reprodutivo (essas espécies não apresentam número de tombo na tabela 1). Dentre as 106 espécies citadas por Almeida et al. (2010) para o campo sujo úmido, 38 não foram encontradas nas outras fisionomias. Assim, o número total estimado de espécies de plantas vasculares para a Estação é de 437 (399 + 38 exclusivas de campo sujo úmido).

\section{Caracterização da flora de cerrado (s.l.)}

Considerando apenas espécies de cerrado (s.l.), foram encontradas 346 espécies distribuídas em 220 gêneros e 87 famílias botânicas, sendo as de maior riqueza Asteraceae (31 espécies), Fabaceae (27), Myrtaceae (26), Melastomataceae (21), Rubiaceae (15), Lauraceae (12), Bignoniaceae (11) e Poaceae (10), que reuniram 153 espécies ou $44,2 \%$ do total.

Em relação ao hábito, 133 espécies são árvores, 100 são ervas, 84 são arbustos, 18 são lianas e 9 são epífitas. Apenas uma espécie de saprófita e uma espécie hemiparasita foram encontradas. As espécies do componente arbóreo estão distribuídas em 88 gêneros e 46 famílias sendo as famílias mais ricas Myrtaceae (19 espécies), Fabaceae (14), Lauraceae (9), Annonaceae (6), Asteraceae e Melastomataceae (5 cada). Já o componente não-arbóreo reuniu 213 espécies de 150 gêneros e 64 famílias, as mais ricas sendo Asteraceae (26 espécies), Melastomataceae (16), Fabaceae (14), Rubiaceae (12), Poaceae (10), Bromeliaceae (8), Malpighiaceae, Myrtaceae (7 espécies cada), Cyperaceae (6), Apocynaceae, Orchidaceae e Solanaceae (5 espécies cada).

\section{Delimitação do cerrado (s.l.) na EEcI}

O cerrado denso apresentou o maior número de espécies (178), seguido pelo cerrado ralo (158), campo sujo úmido (100), cerradão (104) e campo limpo úmido (20). A fisionomia campestre úmida (campo sujo úmido + campo limpo úmido) totalizou 101 espécies. Considerando apenas o estrato herbáceo-arbustivo, a riqueza nesta fisionomia foi de 86 espécies. No conjunto das fisionomias de cerrado (s.l.) de interflúvio e na Floresta Estacional Semidecidual Montana (incluindo dados da Estação Experimental) foram encontradas 148 e 143 espécies herbáceo-arbustivas, respectivamente. O número de espécies herbáceo-arbustivas compartilhadas entre a fisionomia campestre úmida e o cerrado (s.l.) de interflúvio foi de 35 . O número correspondente para a Floresta Estacional Semidecidual Montana foi de apenas 11. As similaridades obtidas com o índice de Sorensen foram de 0,3 entre a fisionomia campestre úmida e o cerrado (s.l.) de interflúvio e de 0,1 entre aquela e a Floresta Estacional Semidecidual Montana. Considerando as fisionomias de cerrado (s.l.) de interflúvio separadamente e a campestre úmida, a menor similaridade foi entre esta e o cerradão e a maior, entre o cerrado ralo e o cerrado denso (Tabela 2). Contudo, as similaridades entre a fisionomia campestre úmida e o cerrado ralo e especialmente, entre a primeira e o cerrado denso, foram maiores do que a similaridade observada entre os extremos fisionômicos de cerrado (s.l.) de interflúvio na EEcI: cerradão e cerrado ralo.

\section{Espécies ameaçadas}

Dentre as 437 espécies registradas em todas as fisionomias da EEcI, oito estão ameaçadas de extinção de acordo com as fontes consultadas (Tabela 3). A distribuição geográfica restrita e a ocorrência desconhecida em unidade de conservação são as causas de ameaça mais frequentes, afetando quatro das oito espécies ameaçadas. Apenas uma espécie, Araucaria angustifolia (Bert.) Kuntze, consta como ameaçada simultaneamente nas listas que consideram os níveis mundial, nacional e estadual. Considerando apenas o nível estadual, são três espécies na categoria "Ameaçada" e três na categoria "Vulnerável".

\section{Limites de distribuição de espécies lenhosas típicas de cerrado (s.l.)}

Dentre espécies apontadas por Bridgewater et al. (2004) como frequentes no cerrado ( s.l.) na província florística do extremo sul do Bioma, não foram encontradas na EEcI: 
Tabela 1. Espécies de plantas vasculares da Estação Ecológica de Itapeva. Fisionomias: C, cerradão; CD, cerrado denso; CLU, campo limpo úmido, CR, cerrado ralo; FESM, Floresta Estacional Semidecidual Montana; FESA, Floresta Estacional Semidecidual Aluvial. SPSF, número de tombo no Herbário Dom Bento Pickel. Asterisco, mata ciliar do rio Pirituba.

Table 1. Vascular plant species of the Ecological Station of Itapeva. Physiognomy, C, woody savanna taller than CD; CD, woody savanna; CLU, grassland swamp savanna; CR, grassland savanna with scattered trees; FESM, Montane Semideciduous Seasonal Forest; FESA, Alluvial Semideciduous Seasonal Forest. SPSF, specimen record number at the Dom Bento Pickel Herbarium. Asterisk, Pirituba riverine forest.

\begin{tabular}{|c|c|c|c|c|}
\hline Família/Espécie & Nome popular & Hábito & Fisionomia & SPSF \\
\hline \multicolumn{5}{|l|}{ ACANTHACEAE } \\
\hline Justicia carnea Lindl. & Justícia & Erva & FESM* & 41146 \\
\hline Ruellia geminiflora Kunth & Ipecaconha & Erva & $\mathrm{CR}$ & \\
\hline \multicolumn{5}{|l|}{ ANACARDIACEAE } \\
\hline Lithraea molleoides (Vell.) Engl. & aroeira-brava & Árvore & $\mathrm{CD}, \mathrm{CR}, \mathrm{FESM}$ & 39591,41513 \\
\hline Schinus terebinthifolius Raddi & aroeira-pimenteira & Árvore & $\mathrm{CD}$ & 41254 \\
\hline Tapirira guianensis Aubl. & peito-de-pombo & Árvore & $\mathrm{C}, \mathrm{CD}, \mathrm{FESA}$ & 39621,41252 \\
\hline \multicolumn{5}{|l|}{ ANNONACEAE } \\
\hline Annona cacans Warm. & araticum-cagão & Árvore & $\mathrm{C}$ & \\
\hline Annona coriacea Mart. & araticum-do-campo & Árvore & $\mathrm{C}$ & \\
\hline Annona crassiflora Mart. & araticum & Árvore & $\mathrm{C}, \mathrm{CD}$ & 39697 \\
\hline Annona dioica A.St.-Hil. & araticum & Árvore & $\mathrm{C}$ & \\
\hline Duguetia furfuracea (A.St.-Hil.) Saff. & marolinho & Arbusto & CLU, CD, FESA & 39738,41466 \\
\hline Duguetia lanceolata A.St.-Hil. & pindaíba & Árvore & $\mathrm{C}$ & \\
\hline Guatteria australis A.St.-Hil. & pindaúva-preta & Árvore & $\mathrm{C}, \mathrm{CD}, \mathrm{FESM}^{*}, \mathrm{FESA}$ & 39767,41130 \\
\hline \multicolumn{5}{|l|}{ APIACEAE } \\
\hline Eryngium canaliculatum Cham. \& Schltdl. & língua-de-tucano & Erva & $\mathrm{CR}, \mathrm{CD}$ & \\
\hline Eryngium elegans Cham. \& Schltdl. & caraguatá-elegante & Erva & $\mathrm{CR}$ & 41572 \\
\hline Eryngium eriophorum Cham. \& Schltdl. & azulzinha & Erva & $\mathrm{CR}$ & 39721 \\
\hline \multicolumn{5}{|l|}{ APOCYNACEAE } \\
\hline Aspidosperma cylindrocarpon Müll. Arg. & peroba-poca & Árvore & FESM & \\
\hline Aspidosperma subincanum Mart. & guatambu-vermelho & Árvore & $\mathrm{C}$ & \\
\hline Aspidosperma tomentosum Mart. & guatambu-do-cerrado & Árvore & CLU, C, CD & 39595,39627 \\
\hline Ditassa warmingii E.Fourn. & & Liana & $\mathrm{CD}$ & 39859 \\
\hline Gonioanthela axillaris (Vell.) Fontella \& E.A.Schwarz & & Liana & FESA & \\
\hline Mandevilla pohliana (Stadelm.) A.H.Gentry & jalapa-do-campo & Erva & $\mathrm{CD}$ & 41247,41249 \\
\hline Oxypetalum appendiculatum Mart. & cipó-leite & Erva & $\mathrm{CD}$ & 39770 \\
\hline Tabernaemontana laeta Mart. & leiteiro & Árvore & FESM & 41511 \\
\hline Temnadenia violacea (Vell.) Miers & cipó-da-flor-lilás & Liana & CLU, C, CD, FESM & 39566,41515 \\
\hline \multicolumn{5}{|l|}{ AQUIFOLIACEAE } \\
\hline Ilex brasiliensis (Spreng.) Loes. & mate-falso & Árvore & FESM*, FESA & 40120,41128 \\
\hline Ilex paraguariensis A.St.-Hil. & erva-mate & Árvore & $\mathrm{CD}$ & 39580,41115 \\
\hline Ilex theaezans Mart. & caúna & Arbusto & $\mathrm{CD}$ & 41120 \\
\hline \multicolumn{5}{|l|}{ ARALIACEAE } \\
\hline Dendropanax cuneatus (DC.) Decne. \& Planch. & maria-mole & Árvore & FESM & \\
\hline Schefflera morototoni (Aubl.) Decne. \& Planch. & morototó & Árvore & FESM & \\
\hline Schefflera vinosa (Cham. \& Schltdl.) Frodin \& Fiaschi & mandioqueiro & Árvore & $\mathrm{C}, \mathrm{CD}, \mathrm{CR}$ & 39607,40514 \\
\hline \multicolumn{5}{|l|}{ ARAUCARIACEAE } \\
\hline Araucaria angustifolia (Bert.) Kuntze & araucária & Árvore & FESM* & \\
\hline \multicolumn{5}{|l|}{ ARECACEAE } \\
\hline Attalea geraensis Barb. Rodr. & $\begin{array}{l}\text { palmeira-indaiá-do- } \\
\text { cerrado }\end{array}$ & Arbusto & $\mathrm{CD}$ & 39727 \\
\hline Geonoma schottiana Drude & gamiova & Arbusto & FESM*, FESA & 40130,40173 \\
\hline Syagrus romanzoffiana (Cham.) Glassm. & jerivá & Árvore & $\mathrm{CD}$ & \\
\hline \multicolumn{5}{|l|}{ ASTERACEAE } \\
\hline Achyrocline satureioides (Lam.) DC. & macela & Arbusto & $\mathrm{CR}$ & 39702 \\
\hline Aspilia heringeriana H.Rob. & margarida-do-campo & Erva & $\mathrm{CR}$ & 41240 \\
\hline Baccharis dentata (Vell.) G.M.Barroso & alecrim-do-campo & Árvore & FESM* & \\
\hline Baccharis dracunculifolia DC. & alecrim & Arbusto & $\mathrm{CR}$ & 39760 \\
\hline
\end{tabular}


Cielo-Filho, R. et al.

Tabela 1. Continuação...

\begin{tabular}{|c|c|c|c|c|}
\hline Família/Espécie & Nome popular & Hábito & Fisionomia & SPSF \\
\hline Baccharis genistelloides (Lam.) Pers. & carqueja & Erva & FESM* & 40562 \\
\hline Baccharis pentziifolia Sch.Bip. ex Baker & vassourão-do-campo & Arbusto & $\mathrm{CD}$ & 39740 \\
\hline Baccharis trimera (Less.) DC. & carqueja-amarga & Arbusto & CLU, CD, CR & 40466,41477 \\
\hline Calea cymosa Less. & margarida-branca & Erva & $\mathrm{CR}$ & 41533 \\
\hline Calea pinnatifida (R.Br.) Baker & erva-de-lagarto & Erva & FESM & \\
\hline Calea triantha (Velloso) Pruski & & Erva & $\mathrm{CR}$ & 39689 \\
\hline Chresta sphaerocephala DC. & chapéu-de-couro & Arbusto & $\mathrm{CD}, \mathrm{CR}$ & 40154,40476 \\
\hline $\begin{array}{l}\text { Chromolaena congesta (Hook. \& Arn.) } \\
\text { R.M.King \& H.Rob. }\end{array}$ & & Arbusto & $\mathrm{CR}$ & 39761 \\
\hline Chromolaena odorata (L.) King \& H.E. Robins. & cromolena & Liana & $\mathrm{C}$ & 39684 \\
\hline Chromolaena subvelutina (DC.) R.I.Esteves & & Arbusto & $\mathrm{CD}$ & 39677 \\
\hline Chrysolaena platensis (Spreng.) H. Rob. & assa-peixe-roxo & Arbusto & $\mathrm{CD}, \mathrm{CR}$ & 39686,41579 \\
\hline Eupatorium sp. & & Erva & $\mathrm{CD}$ & 41467 \\
\hline Gochnatia paniculata (Less.) Cabrera & cambará & Arbusto & $\mathrm{CD}, \mathrm{CR}$ & 40281,40467 \\
\hline Gochnatia polymorpha (Less.) Cabrera & cambará & Árvore & $\mathrm{CD}, \mathrm{CR}$ & 39763,39765 \\
\hline Grazielia multifida (DC.) King \& Robins & eupatório & Erva & $\mathrm{CR}$ & 41161 \\
\hline Mikania oblongifolia DC. & & Arbusto & $\mathrm{CD}$ & 41122 \\
\hline Mikania sessilifolia DC. & & Arbusto & $\mathrm{CR}$ & 39691 \\
\hline $\begin{array}{l}\text { Neocabreria aff. malacophylla (Klatt) } \\
\text { R.M.King \& H.Rob. }\end{array}$ & & Erva & C, FESM* & 40512,40524 \\
\hline Piptocarpha axillaris (Less.) Baker & vassourão & Árvore & $\mathrm{C}, \mathrm{CR}, \mathrm{FESM} *$ & 40295,40480 \\
\hline Piptocarpha macropoda (DC.) Baker & casca-preta-da-folha-larga & Árvore & $\mathrm{C}$ & \\
\hline Piptocarpha regnellii (Sch.Bip.) Cabrera & vassourãozinho & Árvore & $\mathrm{C}$ & \\
\hline Senecio brasiliensis (Spreng.) Less. & maria-mole & Erva & CR & 41532 \\
\hline Symphyopappus cuneatus (DC.) Sch.Bip. ex Baker & eupatório & Arbusto & $\mathrm{CD}, \mathrm{CR}$ & \\
\hline Trixis verbasciformis Less. & arnica-docampo & Erva & $\mathrm{CD}$ & 41469 \\
\hline Vernonia diffusa Less. & cambará-de-casca-preta & Árvore & $\mathrm{C}$ & \\
\hline Vernonia nitidula Less. & cambarazinho & Arbusto & $\mathrm{CD}$ & 39687 \\
\hline Viguiera aff. gardneri Barker & & Erva & $\mathrm{CR}$ & 41166,41587 \\
\hline \multicolumn{5}{|l|}{ BIGNONIACEAE } \\
\hline Cybistax antisyphilitica (Mart.) Mart. & ipê-verde & Árvore & $\mathrm{CD}$ & \\
\hline Fridericia speciosa Mart. & cipó-vermelho & Liana & $\mathrm{CD}$ & 41160 \\
\hline Handroanthus chrysotrichus (Mart. ex A.DC.) Mattos & ipê-amarelo & Árvore & $\mathrm{CD}$ & \\
\hline Handroanthus ochraceus (Cham.) Mattos & ipê-amarelo & Árvore & CLU, C, CD, CR & 40478 \\
\hline Jacaranda aff. macrantha Cham. & caroba & Árvore & $\mathrm{C}$ & \\
\hline Jacaranda caroba (Vell.) A.DC. & caroba-do-campo & Arbusto & CR, FESA & 41248,41257 \\
\hline Jacaranda cuspidifolia Mart. ex DC. & carobinha & Árvore & $\mathrm{CR}$ & 41245 \\
\hline Jacaranda oxyphylla Cham. & caroba-de-são-paulo & Arbusto & $\mathrm{CD}, \mathrm{CR}$ & 39711,40464 \\
\hline $\begin{array}{l}\text { Tabebuia aurea (Silva Manso) } \\
\text { Bent. \& Hook.f. ex S.Moore }\end{array}$ & cinco-folhas & Árvore & $\mathrm{C}$ & \\
\hline Zeyheria montana Mart. & bolsa-de-pastor & Árvore & $\mathrm{CR}$ & 39610,39633 \\
\hline \multicolumn{5}{|l|}{ BORAGINACEAE } \\
\hline Cordia trichotoma (Vell.) Arrab. ex Steud. & louro-pardo & Árvore & $\mathrm{C}$ & \\
\hline Euploca salicoides (Cham.) J.I.M. Melo \& Semir & crisa-de-galo & Erva & $\mathrm{CR}$ & 41578 \\
\hline \multicolumn{5}{|l|}{ BROMELIACEAE } \\
\hline Aechmea distichantha Lem. & caraguatá & Erva & CR & 40472,40475 \\
\hline Ananas ananassoides (Baker) L.B.Sm. & abacaxi-do-cerrado & Erva & $\mathrm{C}$ & \\
\hline Billbergia distachia (Vell) Mez & gravatá & Epífita & FESM* & 41132 \\
\hline Billbergia zebrina (Herb.) Lindl. & bromélia & Epífita & $\mathrm{C}$ & 39748 \\
\hline Bromelia balansae $\mathrm{Mez}$ & caraguatá & Erva & $\mathrm{CD}$ & \\
\hline Dyckia linearifolia Baker & gravatá & Erva & $\mathrm{CR}, \mathrm{CD}$ & 40469,41123 \\
\hline Tillandsia stricta Sol. & gravatazinho & Epífita & CLU, CD & 39628,40156 \\
\hline
\end{tabular}


Tabela 1. Continuação...

\begin{tabular}{|c|c|c|c|c|}
\hline Família/Espécie & Nome popular & Hábito & Fisionomia & SPSF \\
\hline Tillandsia tenuifolia $\mathrm{L}$. & tilandsia & Epífita & $\mathrm{C}, \mathrm{CR}$ & 40468,41098 \\
\hline Vriesea procera (Mart. ex Schult. \& Schult.f.) Wittm. & & Erva & $\mathrm{C}$ & 40580 \\
\hline \multicolumn{5}{|l|}{ CACTACEAE } \\
\hline Cereus hildmannianus K.Schum. & mandacaru & Árvore & $\mathrm{C}$ & \\
\hline \multicolumn{5}{|l|}{ CANNABACEAE } \\
\hline Trema micrantha (L.) Blume & crindiúva & Árvore & FESM & 41508 \\
\hline \multicolumn{5}{|l|}{ CARYOCARACEAE } \\
\hline Caryocar brasiliense Cambess. & pequi & Arbusto & $\mathrm{CD}$ & 39626,41117 \\
\hline \multicolumn{5}{|l|}{ CELASTRACEAE } \\
\hline Maytenus evonymoides Reissek & laranjinha & Árvore & $\mathrm{CD}, \mathrm{FESA}$ & 40298 \\
\hline Maytenus gonoclada Mart. & maytenus & Árvore & $\mathrm{C}$ & 39701 \\
\hline Peritassa campestris (Cambess.) A.C.Sm. & bacupari & Arbusto & $\mathrm{CD}$ & 40513 \\
\hline Peritassa hatschbachii Lombardi & bacupari & Liana & FESM* & 41149 \\
\hline Plenckia populnea Reissek & mangabeira-brava & Árvore & $\mathrm{CD}$ & 41251 \\
\hline \multicolumn{5}{|l|}{ CHLORANTHACEAE } \\
\hline Hedyosmum brasiliense Miq. & chá-de-soldado & Árvore & FESA & 41205 \\
\hline \multicolumn{5}{|l|}{ CHRYSOBALANACEAE } \\
\hline Hirtella hebeclada Moric. ex DC. & macucurana & Árvore & $\mathrm{C}$ & \\
\hline \multicolumn{5}{|l|}{ CLETHRACEAE } \\
\hline Clethra scabra Pers. & guaperê & Árvore & $\mathrm{CR}$ & 39636 \\
\hline \multicolumn{5}{|l|}{ CLUSIACEAE } \\
\hline Clusia criuva Cambess. & $\begin{array}{l}\text { folha-dura-da-pedra- } \\
\text { grande }\end{array}$ & Árvore & FESM* & 41213 \\
\hline Kielmeyera coriacea Mart. & para-tudo & Árvore & $\mathrm{C}, \mathrm{CD}, \mathrm{CR}$ & 39745,41234 \\
\hline Kielmeyera variabilis Mart.\& Zucc. & pau-santo & Árvore & $\mathrm{CD}$ & \\
\hline \multicolumn{5}{|l|}{ COMBRETACEAE } \\
\hline Terminalia triflora (Griseb.) Lillo & amarelinho & Árvore & FESM* & \\
\hline \multicolumn{5}{|l|}{ COMMELINACEAE } \\
\hline Commelina erecta $\mathrm{L}$. & trapoeraba-azul & Erva & $\mathrm{CD}, \mathrm{FESA}$ & 40270,41560 \\
\hline \multicolumn{5}{|l|}{ CONVOLVULACEAE } \\
\hline Ipomoea delphinioides Choisy & ipoméia & Liana & $\mathrm{CD}, \mathrm{CR}$ & 41106,41577 \\
\hline Jacquemontia ferruginea Choisy & & Erva & $\mathrm{C}, \mathrm{CR}$ & 39714,41529 \\
\hline Merremia contorquens (Choisy) Hallier f. & & Erva & $\mathrm{CD}, \mathrm{CR}$ & 39681,39750 \\
\hline \multicolumn{5}{|l|}{ CUCURBITACEAE } \\
\hline Cayaponia espelina (Silva Manso) Cogn. & espelina-verdadeira & Erva & $\mathrm{C}, \mathrm{CD}, \mathrm{CR}$ & 39620,41574 \\
\hline Melancium campestre Naudin & melancia-do-campo & Erva & $\mathrm{CD}$ & \\
\hline \multicolumn{5}{|l|}{ CUNONIACEAE } \\
\hline Lamanonia ternata Vell. & cangalheiro & Árvore & C, FESM* & 40180,41140 \\
\hline \multicolumn{5}{|l|}{ CYPERACEAE } \\
\hline Lagenocarpus sp. & & Erva & FESA & 41557 \\
\hline Rhynchospora consanguinea (Kunth) Boeck. & & Erva & CR, FESA & 41552 \\
\hline Rhynchospora corymbosa (L.) Britton & capituva & Erva & CD, FESA & 40146 \\
\hline Rhynchospora exaltata Kunth & periperi & Erva & $\mathrm{CD}$ & 41108 \\
\hline Rhynchospora globosa (Kunth) Roem. \& Schult. & espeta-nariz & Erva & FESA & 41554 \\
\hline Rhynchospora splendens Lindm. & capim-navalha & Erva & FESA & 40128 \\
\hline \multicolumn{5}{|l|}{ DENNSTAEDTIACEAE } \\
\hline Pteridium aquilinum (L.) Kuhn & samambaia-das-taperas & Erva & $\mathrm{CD}$ & \\
\hline \multicolumn{5}{|l|}{ DILLENIACEAE } \\
\hline Davilla elliptica A.St.-Hil. & cipó-caboclo & Liana & $\mathrm{CD}$ & 39612 \\
\hline Davilla rugosa Poir. & cipó-caboclo & Liana & $\mathrm{C}$ & 39564 \\
\hline DIOSCOREACEAE & & & & \\
\hline
\end{tabular}


Cielo-Filho, R. et al.

Tabela 1. Continuação...

\begin{tabular}{|c|c|c|c|c|}
\hline Família/Espécie & Nome popular & Hábito & Fisionomia & SPSF \\
\hline Dioscorea amaranthoides C.Presl & cará & Liana & $\mathrm{C}$ & 39762 \\
\hline \multicolumn{5}{|l|}{ EBENACEAE } \\
\hline Diospyros hispida A.DC. & caqui-do-cerrado & Árvore & $\mathrm{CD}, \mathrm{CR}$ & \\
\hline \multicolumn{5}{|l|}{ ERICACEAE } \\
\hline Gaylussacia brasiliensis (Spreng.) Meisn. & camarinha & Arbusto & CR & 39616 \\
\hline \multicolumn{5}{|l|}{ ERIOCAULACEAE } \\
\hline Eriocaulon gomphrenoides Kunt & & Erva & CLU & 40497 \\
\hline Syngonanthus xeranthemoides (Boing.) Ruhland & jazida-do-brejo & Erva & CLU, FESA & 41553 \\
\hline \multicolumn{5}{|l|}{ ERYTHROXYLACEAE } \\
\hline Erythroxylum cuneifolium (Mart.) O.E.Schulz & mercúrio & Arbusto & $\mathrm{CD}$ & 39769,41238 \\
\hline Erythroxylum deciduum A.St.-Hil. & cocão & Árvore & $\mathrm{CD}, \mathrm{CR}$ & 40485,41242 \\
\hline Erythroxylum suberosum A.St.-Hil. & galinha-choca & Arbusto & $\mathrm{CD}$ & \\
\hline \multicolumn{5}{|l|}{ ESCALLONIACEAE } \\
\hline Escallonia farinacea A.St.-Hil. var. farinacea & esponja-do-mato & Arbusto & $\mathrm{CD}$ & 41573 \\
\hline \multicolumn{5}{|l|}{ EUPHORBIACEAE } \\
\hline Alchornea triplinervia (Spreng.) Müll.Arg. & tapiá & Árvore & FESM & \\
\hline Croton serpyllifolius Baill. & & Arbusto & CR & 41168 \\
\hline Microstachys daphnoides (Mart) Müll.Arg. & & Erva & $\mathrm{CR}$ & 39749 \\
\hline Pera glabrata (Schott) Poepp. ex Baill & tamanqueira & Árvore & CD, FESA & \\
\hline Sebastiania brasiliensis Spreng. & branquilho & Árvore & FESM & \\
\hline $\begin{array}{l}\text { Sebastiania commersoniana (Baill.) } \\
\text { L.B.Sm. \& Downs }\end{array}$ & branquilha & Arbusto & FESM* & 41137,41144 \\
\hline \multicolumn{5}{|l|}{ FABACEAE-CAESALPINIOIDEAE } \\
\hline Cassia ferruginea (Schrad.) Schrad. ex DC. & chuva-de-ouro & Árvore & CD, FESM & \\
\hline $\begin{array}{l}\text { Chamaecrista cathartica (Mart.) } \\
\text { H.S.Irwin \& Barneby }\end{array}$ & sene-do-campo & Arbusto & CLU, CD & 39602,41547 \\
\hline Chamaecrista desvauxii (Collad.) Killip & sene & Arbusto & $\mathrm{CD}$ & 39569 \\
\hline $\begin{array}{l}\text { Chamaecrista desvauxii (Collad.) Killip var. } \\
\text { langsdorffii ( Kunth ex Vogel) Irwin \& Barneby }\end{array}$ & sene & Erva & $\mathrm{CR}$ & 41173 \\
\hline Copaifera langsdorffii Desf. & copaíba & Árvore & $\mathrm{CD}$ & \\
\hline Senna rugosa (G.Don) H.S.Irwin \& Barneby & manduirana-do-cerrado & Arbusto & $\mathrm{CD}, \mathrm{CR}$ & 39615,40152 \\
\hline Senna splendida (Vogel) H.S.Irwin \& Barneby & manduirana & Arbusto & $\mathrm{C}, \mathrm{CD}$ & 39724,39812 \\
\hline Tachigali denudata (Vogel) Oliveira-Filho & angá & Árvore & FESM* & 40177 \\
\hline \multicolumn{5}{|l|}{ FABACEAE-CERCIDEAE } \\
\hline Bauhinia longifolia (Bong.) Steud. & pata-de-vaca-do-campo & Árvore & $\mathrm{C}, \mathrm{CD}, \mathrm{FESM} *, \mathrm{FESM}$ & \\
\hline Bauhinia rufa (Bong.) Steud. & pata-de-vaca & Árvore & $\mathrm{C}, \mathrm{CR}$ & 39752,41544 \\
\hline \multicolumn{5}{|l|}{ FABACEAE-FABOIDEAE } \\
\hline Acosmium subelegans (Mohlenbr.) Yakovlev & amendoim-falso & Árvore & $\mathrm{CD}$ & 41195 \\
\hline Andira humilis Mart. ex Benth. & angelim-do-campo & Árvore & $\mathrm{CR}$ & 39583 \\
\hline Camptosema scarlatinum (Mart. ex Benth.) Burkart & bico-de-papagaio & Liana & $\mathrm{C}, \mathrm{CR}, \mathrm{FESM}$ & 39718,41517 \\
\hline Centrosema bracteosum Benth. & rabo-de-tatu & Arbusto & FESA & 41541 \\
\hline Crotalaria micans Link & guizo-de-cascavel & Erva & $\mathrm{CR}$ & 39707 \\
\hline Dalbergia miscolobium Benth. & caviúna-do-campo & Árvore & $\mathrm{CD}, \mathrm{CR}$ & 39618,39698 \\
\hline Eriosema heterophyllum Benth. & feijão-bravo & Erva & $\mathrm{CR}$ & 40477,41200 \\
\hline Machaerium acutifolium Benth. & jacarandá-do-campo & Árvore & $\mathrm{C}, \mathrm{CD}, \mathrm{CR}$ & 39630,41092 \\
\hline Machaerium brasiliense Hoehne & sapuva & Árvore & CLU, C, FESM* & 39603 \\
\hline Machaerium hirtum (Vell.) Stellfeld & barreiro & Árvore & FESM & \\
\hline Machaerium nictitans (Vell.) Benth. & bico-de-andorinha & Árvore & $\mathrm{C}, \mathrm{CD}, \mathrm{FESM}{ }^{*}$ & \\
\hline Ormosia arborea (Vell.) Harms & olho-de-cabra & Árvore & FESM* & \\
\hline Periandra mediterranea (Vell.) Taub. & alcaçuz-do-cerrado & Arbusto & $\mathrm{C}, \mathrm{CD}$ & 39619,39625 \\
\hline Vigna peduncularis Kunth & feijão-do-mato & Liana & $\mathrm{CD}$ & 40110 \\
\hline FABACEAE-MIMOSOIDEAE & & & & \\
\hline
\end{tabular}


Tabela 1. Continuação...

\begin{tabular}{|c|c|c|c|c|}
\hline Família/Espécie & Nome popular & Hábito & Fisionomia & SPSF \\
\hline Anadenanthera colubrina (Vell.) Brenan & angico-branco & Árvore & FESM* & 41129,41141 \\
\hline $\begin{array}{l}\text { Anadenanthera peregrina var. falcata (Benth.) } \\
\text { Altschul }\end{array}$ & angico-do-cerrado & Árvore & $\mathrm{CD}, \mathrm{CR}$ & 39609,40455 \\
\hline Calliandra dysantha Benth. & flor-de-caboclo & Arbusto & $\mathrm{CD}, \mathrm{CR}$ & 39731,40488 \\
\hline Inga marginata Willd. & ingá-feijão & Árvore & FESM* & 40540 \\
\hline Leucochlorom incuriale (Vell.) Barneby \& J.W.Grimes & angico-rajado & Árvore & FESM* & \\
\hline Mimosa debilis Humb. \& Bonpl. ex Willd. var. debilis & juquiri & Arbusto & $\mathrm{CD}$ & 41474 \\
\hline Mimosa dolens Vell. & juquiri & Arbusto & CLU, CR & 39564, 39699 \\
\hline Mimosa furfuracea Benth. & & Árvore & CR & 40474 \\
\hline Mimosa micropteris Benth. & & Arbusto & $\mathrm{CD}$ & 41471,41538 \\
\hline Piptadenia gonoacantha (Mart.) J.F.Macbr. & pau-jacaré & Árvore & FESM & \\
\hline Stryphnodendron adstringens (Mart.) J.F.Macbr. & barbatimão-verdadeiro & Árvore & $\mathrm{CD}, \mathrm{CR}$ & 40481,41253 \\
\hline Stryphnodendron obovatum Benth. & barbatimão & Árvore & $\mathrm{CR}$ & 39631 \\
\hline \multicolumn{5}{|l|}{ GENTIANACEAE } \\
\hline Adenolisianthus arboreus (Spruce ex Progel) Gilg & genciana-da-terra & Erva & $\mathrm{CR}$ & 41539 \\
\hline Irlbachia oblongifolia (Mart.) Maas & genciana-do-campo & Erva & FESA & 41311 \\
\hline Voyria aphylla (Jacq.) Pers. & angélica-do-mato & Saprófita & $\mathrm{C}$ & 39757 \\
\hline Voyria tenella Hook. & angélica-lilás & Saprófita & FESA & 40277 \\
\hline \multicolumn{5}{|l|}{ GESNERIACEAE } \\
\hline Sinningia allagophylla (Mart.) Wiehler & cravo-do-campo & Erva & FESM & \\
\hline \multicolumn{5}{|l|}{ HYPERICACEAE } \\
\hline Hypericum brasiliense Choisy & alecrim-bravo & Erva & $\mathrm{CD}$ & 40165 \\
\hline \multicolumn{5}{|l|}{ IRIDACEAE } \\
\hline Alophia sellowiana Klatt & lírio-branco-do-brasil & Erva & $\mathrm{CD}$ & 40462 \\
\hline Neomarica rigida (Ravenna) Capellari Jr. & neomarica-espetada & Erva & FESM* & 41142 \\
\hline Sisyrinchium vaginatum Spreng. & capim-reis & Erva & $\mathrm{CD}$ & 40169 \\
\hline Trimezia juncifolia (Klatt) Benth. \& Hook. & ruibarbo-amarelo & Erva & $\mathrm{CD}, \mathrm{CR}$ & 41116,41545 \\
\hline \multicolumn{5}{|l|}{ LAMIACEAE } \\
\hline Aegiphila lhotskiana Cham. & tamanqueira & Árvore & CLU, C, CD & 39601,41118 \\
\hline Aegiphila verticillata Vell. & papagaio & Árvore & $\mathrm{CR}$ & \\
\hline Hyptis caespitosa A.St.-Hil. ex Benth. & & Erva & CR, FESA & 41535,41555 \\
\hline Rhabdocaulon lavanduloides (Benth.) Epling & & Erva & $\mathrm{CD}$ & 40167 \\
\hline Vitex megapotamica (Spreng.) Moldenke & azeitona-do-mato & Árvore & FESM* & \\
\hline Vitex polygama Cham. & maria-preta & Árvore & $\mathrm{C}, \mathrm{CD}, \mathrm{FESM}^{*}$ & \\
\hline \multicolumn{5}{|l|}{ LAURACEAE } \\
\hline Cinnamomum sellowianum (Nees \& Mart.) Kosterm. & canela & Árvore & $\mathrm{C}, \mathrm{CR}, \mathrm{FESM} *$ & \\
\hline Endlicheria paniculata (Spreng.) J.F.Macbr. & canela-do-brejo & Árvore & FESM & \\
\hline Nectandra lanceolata Nees & canelão-amarelo & Árvore & FESM & 41216 \\
\hline Nectandra megapotamica (Spreng.) Mez & canelinha-de-cheiro & Árvore & $\mathrm{CD}$ & \\
\hline Nectandra oppositifolia Nees & canela-ferrugem & Árvore & FESM & \\
\hline Ocotea bicolor Vattimo-Gil & canela & Árvore & $\mathrm{C}, \mathrm{CD}, \mathrm{FESM}^{*}$ & 40170 \\
\hline Ocotea corymbosa (Meisn.)Mez & canelinha-do-cerrado & Árvore & $\mathrm{C}, \mathrm{CD}, \mathrm{CR}$ & 39605,42500 \\
\hline Ocotea lancifolia (Schott) Mez & canela-sabão & Árvore & $\mathrm{CD}, \mathrm{FESA}$ & 40123,40162 \\
\hline Ocotea odorifera (Vell.) Rohwer & canela-sassafras & Árvore & FESM & \\
\hline Ocotea pulchella (Nees \& Mart.) Mez & canela-do-cerrado & Árvore & $\mathrm{C}, \mathrm{CD}, \mathrm{CR}$ & 39604,41244 \\
\hline Ocotea tristis (Nees \& Mart.) Mez & canelinha & Arbusto & $\mathrm{CD}, \mathrm{CR}$ & 39606,41473 \\
\hline Persea alba Nees & & Árvore & $\mathrm{C}, \mathrm{CD}, \mathrm{CR}$ & 41111 \\
\hline Persea fulva var. strigosifolia L.E.Kopp & & Árvore & $\mathrm{CD}, \mathrm{CR}$ & 40134,40161 \\
\hline Persea venosa Nees \& Mart. & pau-andrade & Arbusto & $\mathrm{CD}$ & 41255 \\
\hline Persea willdenovii Kosterm. & abacateiro-do-mato & Árvore & $\mathrm{C}, \mathrm{CD}, \mathrm{FESM}$ & 41476,42501 \\
\hline LENTIBULARIACEAE & & & & \\
\hline
\end{tabular}


Cielo-Filho, R. et al.

Tabela 1. Continuação...

\begin{tabular}{|c|c|c|c|c|}
\hline Família/Espécie & Nome popular & Hábito & Fisionomia & SPSF \\
\hline Utricularia tricolor A.St.-Hil. & utricularia & Erva & FESA & 41558 \\
\hline \multicolumn{5}{|l|}{ LORANTHACEAE } \\
\hline Struthanthus vulgaris Mart. & erva-de-passarinho & Hemiparasita & $\mathrm{C}$ & 41089 \\
\hline \multicolumn{5}{|l|}{ LYCOPODIACEAE } \\
\hline Lycopodiella camporum B. Øllg. \& P.G.Windisch & pinheirinho & Erva & CLU & \\
\hline Lycopodium clavatum $\mathrm{L}$. & licopódio & Erva & $\mathrm{CR}$ & 40223 \\
\hline \multicolumn{5}{|l|}{ LYTHRACEAE } \\
\hline $\begin{array}{l}\text { Cuphea calophylla Cham. \& Schltdl. ssp. mesostemon } \\
\text { (Koehne) Lourteig }\end{array}$ & erva-de-bicho & Erva & $\mathrm{CD}$ & 39831 \\
\hline Cuphea racemosa (L.f.) Spreng. & sete-sangrias & Erva & FESM* & 41139 \\
\hline Lafoensia nummularifolia A.St.-Hil. & dedaleira-branca & Arbusto & CLU, CD, CR & 39572,41472 \\
\hline Lafoensia pacari A.St.-Hil. & dedaleiro & Árvore & $\mathrm{CD}$ & \\
\hline \multicolumn{5}{|l|}{ MAGNOLIACEAE } \\
\hline Magnolia ovata (A.St.-Hil.) Spreng. & magnólia-do-brejo & Árvore & CD, FESA & \\
\hline \multicolumn{5}{|l|}{ MALPIGHIACEAE } \\
\hline Banisteriopsis laevifolia (A.Juss.) B.Gates & cipó-prata & Arbusto & $\mathrm{CR}$ & 39730,39732 \\
\hline Byrsonima coccolobifolia Kunth & murici & Arbusto & $\mathrm{C}, \mathrm{CD}, \mathrm{CR}$ & 39579,41528 \\
\hline Byrsonima intermedia A.Juss. & canjica & Arbusto & $\mathrm{CD}, \mathrm{CR}$ & 39768,41110 \\
\hline Byrsonima verbascifolia (L) DC. & murici & Arbusto & $\mathrm{CR}$ & 41542 \\
\hline Heteropterys dumetorum Nied. & & Arbusto & $\mathrm{CR}$ & 41534 \\
\hline Heteropterys umbellata A.Juss. & pedra-única & Arbusto & $\mathrm{CD}, \mathrm{CR}$ & 41159,41169 \\
\hline Hiraea cf. fagifolia (DC.) A.Juss. & & Liana & FESM* & 41150 \\
\hline Peixotoa parviflora A.Juss. & & Liana & $\mathrm{C}, \mathrm{CD}, \mathrm{CR}$ & 39739,41575 \\
\hline \multicolumn{5}{|l|}{ MALVACEAE } \\
\hline Abutilon costicalyx K. Schum. ex. Bakerf. & & Arbusto & FESM* & 41147 \\
\hline Guazuma ulmifolia Lam. & mutambo & Árvore & FESM & \\
\hline Helicteres ovata Lam. & sebastião-da-arruda & Árvore & $\mathrm{C}, \mathrm{FESM}$ & 41103,41521 \\
\hline Peltaea edouardii (Hochr.) Krapov.\& Cristóbal & & Erva & $\mathrm{CD}$ & 41464 \\
\hline Pseudobombax grandiflorum (Cav.) A.Robyns & embiruçu & Árvore & FESM* & \\
\hline Sida linifolia Cav. & linho-do-campo & Erva & $\mathrm{CD}$ & 39700,40279 \\
\hline Sida urens L. & & Erva & $\mathrm{CD}$ & 39679 \\
\hline Waltheria carpinifolia A.St.-Hil. e Naudin & malva & Arbusto & $\mathrm{CR}$ & 41174,41580 \\
\hline Luehea candicans Mart. & açoita-cavalo & Árvore & $\mathrm{C}$ & \\
\hline Luehea divaricata Mart. & açoita-cavalo & Árvore & FESM & \\
\hline Luehea grandiflora Mart. & açoita-cavalo-do-cerrado & Árvore & $\mathrm{CD}$ & 39613 \\
\hline \multicolumn{5}{|l|}{ MELASTOMATACEAE } \\
\hline Acisanthera alsinaefolia (DC.) Triana & quaresmeira-do-brejo & Erva & CR & 41163 \\
\hline Leandra aurea (Cham.) Cogn. & & Arbusto & $\mathrm{C}, \mathrm{CD}, \mathrm{CR}$ & 39744,41109 \\
\hline Leandra melastomoides Raddi & & Árvore & $\mathrm{C}, \mathrm{CD}$ & 39728,41157 \\
\hline Leandra purpurascens (DC.) Cogn. & pixirica & Arbusto & $\mathrm{C}, \mathrm{CD}$ & 40511,41124 \\
\hline Miconia albicans Steud. & quaresmeira-branca & Árvore & $\mathrm{CD}$ & 40516,41551 \\
\hline Miconia hyemalis A.St.-Hil. \& Naudin ex Naudin & pixirica-branca & Arbusto & $\mathrm{CD}$ & 40157,41105 \\
\hline Miconia ligustroides (DC.) Naudin & jacatirão-do-brejo & Arbusto & $\mathrm{C}, \mathrm{CD}, \mathrm{CR}$ & 39726,41203 \\
\hline Miconia sellowiana Naudin & jacatirão & Árvore & $\mathrm{C}, \mathrm{CD}, \mathrm{FESM}^{*}$ & 40456,41527 \\
\hline Miconia theaezans Cogn. & jacatirão-branco & Arbusto & CLU, C, FESA & 39734,40310 \\
\hline Microlepis oleifolia (DC.) Triana & & Arbusto & $\mathrm{CR}$ & 39674 \\
\hline Microlicia isophylla DC. & & Erva & CLU & \\
\hline Rhynchanthera dichotoma DC. & são-joãozinho & Erva & $\mathrm{CD}$ & 39819 \\
\hline Tibouchina sebastianopolitana (Raddi) Cogn & quaresmeira-do-campo & Arbusto & $\mathrm{CR}$ & 39693 \\
\hline Tibouchina gracilis (Bonpl.) Cogn. & quaresmeira-do-brejo & Erva & CR, FESA & 41162,41531 \\
\hline Tibouchina granulosa (Desf.) Cogn. & quaresmeira-rosa & Árvore & $\mathrm{C}$ & \\
\hline
\end{tabular}


Tabela 1. Continuação...

\begin{tabular}{|c|c|c|c|c|}
\hline Família/Espécie & Nome popular & Hábito & Fisionomia & SPSF \\
\hline Tibouchina martialis Cogn. & quaresmeira & Arbusto & $\mathrm{CR}$ & 41537 \\
\hline Tibouchina stenocarpa Cogn. & quaresmeira & Árvore & $\mathrm{C}, \mathrm{CR}$ & 39567,39712 \\
\hline \multicolumn{5}{|l|}{ MELIACEAE } \\
\hline Cedrela odorata $\mathrm{L}$. & cedro-do-brejo & Árvore & FESA & \\
\hline $\begin{array}{l}\text { Guarea macrophylla Vahl ssp. tuberculata (Vell.) } \\
\text { Penn. }\end{array}$ & marinheiro & Árvore & FESM*, FESA & 40300,40499 \\
\hline \multicolumn{5}{|l|}{ MENISPERMACEAE } \\
\hline Cissampelos ovalifolia DC. & orelha-de-onça & Arbusto & $\mathrm{CD}$ & 41256 \\
\hline \multicolumn{5}{|l|}{ MONIMIACEAE } \\
\hline Mollinedia micrantha Perkins & pimentinha & Arbusto & $\mathrm{C}$ & 41102 \\
\hline Mollinedia schottiana (Spreng.) Perkins & pimenteira & Arbusto & $\mathrm{C}$ & 41100 \\
\hline \multicolumn{5}{|l|}{ MORACEAE } \\
\hline Brosimum gaudichaudii Trécul & mama-de-cadela & Árvore & $\mathrm{CD}$ & 40487,41468 \\
\hline Ficus enormis (Mart. Ex Miq.) Mart. & figueira-vermelha & Árvore & $\mathrm{C}, \mathrm{CD}, \mathrm{FESM}^{*}$ & 40175 \\
\hline $\begin{array}{l}\text { Maclura tinctoria (L.) D.Don ex Steud. subsp. } \\
\text { tinctoria }\end{array}$ & taiúva & Árvore & FESM & \\
\hline Sorocea bonplandii (Baill.) W.C.Burger & canxim & Árvore & FESM* & 40558 \\
\hline \multicolumn{5}{|l|}{ MYRTACEAE } \\
\hline Blepharocalyx salicifolius (Kunth) O.Berg & murta-brasileira & Árvore & FESM & \\
\hline Calycorectes psidiiflorus (O.Berg) Sobral & cambuí & Árvore & FESM* & 41865,41866 \\
\hline Calyptranthes concinna DC. & guamirim-facho & Árvore & $\mathrm{CD}, \mathrm{CR}, \mathrm{FESM} *$ & 41826,41927 \\
\hline Campomanesia guaviroba Kiaersk. & gabiroba & Árvore & CD, FESM & 41832 \\
\hline Campomanesia pubescens (DC.) O.Berg & gabiroba-do-campo & Árvore & $\mathrm{CD}$ & 41853,41910 \\
\hline Eugenia bimarginata DC. & falsa-cagaita & Árvore & $\mathrm{C}, \mathrm{CD}$ & 41846,41849 \\
\hline Eugenia calycina Cambess. & & Arbusto & $\mathrm{CD}, \mathrm{CR}$ & 41576,41856 \\
\hline Eugenia hiemalis Cambess. & cambuí-do-campo & Árvore & FESM* & 41934 \\
\hline Eugenia involucrata DC. & cerejereira & Árvore & FESM* & 41827 \\
\hline Eugenia ligustrina (Sw.) Willd. & eugenia & Árvore & FESM* & 41818 \\
\hline Eugenia livida O.Berg & eugenia & Arbusto & $\mathrm{CD}$ & 41933 \\
\hline Eugenia pitanga (O.Berg) Kiaersk. & pitanga-do-cerrado & Arbusto & $\mathrm{C}, \mathrm{CD}, \mathrm{CR}$ & 41851,41928 \\
\hline Eugenia punicifolia (Kunth) DC. & cereja-do-cerrado & Árvore & $\mathrm{CD}$ & \\
\hline Eugenia suberosa Cambess. & & Arbusto & $\mathrm{CD}$ & \\
\hline Hexachlamys edulis (O.Berg) Kausel \& D.Legrand & uvaia-do-cerrado & Árvore & $\mathrm{C}$ & \\
\hline Myrcia albotomentosa Cambess. & myrcia & Árvore & $\mathrm{C}, \mathrm{CD}, \mathrm{FESM}^{*}$ & 41886,41911 \\
\hline Myrcia guianensis (Aubl.) DC. & guamirim-vermelho & Árvore & $\mathrm{C}, \mathrm{CR}$ & 41843,41901 \\
\hline Myrcia hartwegiana (O.Berg) Kiaersk. & & Árvore & CD, FESA & 41840,41864 \\
\hline Myrcia laruotteana Cambess. & cambuí & Arbusto & FESM*, FESA & 41829,41863 \\
\hline Myrcia multiflora (Lam.) DC. & cambuí & Árvore & $\mathrm{CD}, \mathrm{CR}, \mathrm{FESM}{ }^{*}$ & 41900 \\
\hline Myrcia obtecta (O.Berg) Kiaersk. & guamirim-branco & Árvore & $\mathrm{CD}$ & \\
\hline Myrcia pulchra Kiaersk. & & Árvore & $\mathrm{C}, \mathrm{CR}$ & 41831,41897 \\
\hline Myrcia tomentosa (Aublet) DC. & goiabeira-brava & Árvore & $\mathrm{CD}$ & \\
\hline Myrcia venulosa DC. & guamirim & Árvore & $\mathrm{CD}, \mathrm{CR}, \mathrm{FESM}{ }^{*}$ & 41837,41892 \\
\hline Myrciaria tenella (DC.) O.Berg & cambuí & Árvore & CR, FESM* & 41828,41902 \\
\hline Psidium australe Cambess. & araça & Arbusto & $\mathrm{CD}, \mathrm{CR}$ & 41855,41912 \\
\hline Psidium cupreum O.Berg & & Árvore & FESM* & 41825 \\
\hline Psidium grandifolium DC. & araçá & Arbusto & CD, CR, FESA, FESM & 41859,41908 \\
\hline Psidium guianense Pers. & araçá & Arbusto & $\mathrm{CR}$ & 41860 \\
\hline Psidium laruotteanum Cambess. & & Árvore & $\mathrm{C}, \mathrm{CD}, \mathrm{CR}, \mathrm{FESM} *$ & 41830,41932 \\
\hline Psidium rufum O.Berg & araçá-roxo & Árvore & $\mathrm{C}$ & \\
\hline \multicolumn{5}{|l|}{ NYCTAGINACEAE } \\
\hline Guapira opposita (Vell.) Reitz & maria-mole & Árvore & $\mathrm{C}$ & \\
\hline OCHNACEAE & & & & \\
\hline
\end{tabular}


Cielo-Filho, R. et al.

Tabela 1. Continuação...

\begin{tabular}{|c|c|c|c|c|}
\hline Família/Espécie & Nome popular & Hábito & Fisionomia & SPSF \\
\hline Ouratea cf. salicifolia (A.St.-Hil. \& Tull.) Engler & guaraparim & Arbusto & $\mathrm{CD}$ & 39845 \\
\hline Ouratea spectabilis Engl. & batiputá & Árvore & CLU, C, CD & 39592,41097 \\
\hline \multicolumn{5}{|l|}{ OLEACEAE } \\
\hline Chionanthus filiformis (Vell.) P.S.Green & carne-de-vaca & Árvore & FESM* & \\
\hline \multicolumn{5}{|l|}{ ONAGRACEAE } \\
\hline Ludwigia nervosa (Poir.) H.Hara & cruz-de-malta & Erva & $\mathrm{CD}$ & 40271 \\
\hline Ludwigia sericea (Cambess.) H.Hara & cruz-de-malta & Arbusto & $\mathrm{CD}$ & 40269,41548 \\
\hline \multicolumn{5}{|l|}{ ORCHIDACEAE } \\
\hline Epidendrum denticulatum Barb.Rodr. & epidendro & Erva & $\mathrm{C}, \mathrm{CR}$ & 39751,40495 \\
\hline Gomesa flexuosa (Sims) M.W.Chase \& N.H.Williams & & Epífita & $\mathrm{C}$ & 40494 \\
\hline $\begin{array}{l}\text { Gomesa paranapiacabensis (Hoehne) M.W.Chase } \\
\& \text { N.H.Williams }\end{array}$ & & Epífita & CR & 39600 \\
\hline Leptotes bicolor Lindl. & & Epífita & FESA & 40275 \\
\hline Pelexia orthosepala (Rchb.f.\& Warm.) Schltr. & & Erva & $\mathrm{CD}$ & 43802 \\
\hline Polystachya cf. bradei Schltr. & & Epífita & FESA & 40503 \\
\hline \multicolumn{5}{|l|}{ OXALIDACEAE } \\
\hline Oxalis cytisoides Zucc. & & Erva & FESM* & 41136 \\
\hline \multicolumn{5}{|l|}{ PASSIFLORACEAE } \\
\hline Piriqueta rosea (Camb.) Urb. & piriqueta & Erva & $\mathrm{CD}$ & 40150 \\
\hline Piriqueta taubatensis (Urb.) Arbo & & Erva & CR & 41581 \\
\hline \multicolumn{5}{|l|}{ PHYLLANTHACEAE } \\
\hline Hyeronima alchorneoides Allemão & urucurana & Árvore & FESM & \\
\hline \multicolumn{5}{|l|}{ PIPERACEAE } \\
\hline Piper gaudichaudianum Kunth & jaborandi & Arbusto & FESM & \\
\hline \multicolumn{5}{|l|}{ PLANTAGINACEAE } \\
\hline $\begin{array}{l}\text { Mecardonia procumbens (Mill). Small var. cespitosa } \\
\text { (Cham) V.C.Sousa }\end{array}$ & & Erva & $\mathrm{CD}$ & 40515 \\
\hline \multicolumn{5}{|l|}{ POACEAE } \\
\hline Andropogon glaziovii Hack & & Erva & $\mathrm{CD}$ & 39673 \\
\hline Axonopus brasiliensis Kuhlm & & Erva & $\mathrm{CR}$ & 41170 \\
\hline Ctenium polystachyum Balansa & & Erva & $\mathrm{CD}$ & 39688 \\
\hline Eustachys retusa (Lag.) Kunth & & Erva & $\mathrm{CD}$ & 41373 \\
\hline Ichnanthus calvescens (Ness ex Trin.) Döll & & Erva & FESM* & 41133 \\
\hline Ichnanthus procurrens (Ness ex Trin.) Swallen & & Erva & FESM* & 41374 \\
\hline Setaria scabrifolia Kunth & & Erva & $\mathrm{CD}$ & 39676 \\
\hline \multicolumn{5}{|l|}{ PODOCARPACEAE } \\
\hline Podocarpus sellowii Klotzsch ex Endl. & podocarpo & Árvore & $\mathrm{CD}, \mathrm{CR}$ & 40473 \\
\hline \multicolumn{5}{|l|}{ POLYGALACEAE } \\
\hline Monnina richardiana A.St.-Hil. \& Moq. & & Erva & FESA & 40278 \\
\hline \multicolumn{5}{|l|}{ POLYPODIACEAE } \\
\hline Microgramma squamulosa (Kaulf.) de la Sota & cipó-cabeludo & Epífita & CD, FESM & 40579,41523 \\
\hline Pleopeltis hirsutissima (Raddi) de la Sota & polipódio-hirsutíssimo & Epífita & $\mathrm{C}, \mathrm{CD}$ & 40509,40537 \\
\hline Pleopeltis pleopeltifolia (Raddi) Alston & samambaia & Epífita & $\mathrm{C}$ & 40508 \\
\hline \multicolumn{5}{|l|}{ PRIMULACEAE } \\
\hline Cybianthus densicomus Mart. & tintarana & Arbusto & CD, FESM* & 40290,41127 \\
\hline Myrsine balansae (Mez) Arechav. & capororoca & Árvore & FESM & \\
\hline Myrsine coriacea (Sw.) R. Br. ex Roem. \& Schult. & capororoca & Árvore & $\mathrm{C}, \mathrm{CD}, \mathrm{CR}, \mathrm{FESA}$ & 39629,41114 \\
\hline Myrsine gardneriana A.DC. & capororoca & Árvore & $\mathrm{C}, \mathrm{CD}, \mathrm{FESA}$ & 40274 \\
\hline Myrsine lancifolia Mart. & capororoca & Árvore & C, FESM & \\
\hline Myrsine umbellata Mart. & capororoca & Árvore & $\begin{array}{l}\text { C, CD, CR, FESA, } \\
\text { FESM }\end{array}$ & 9634,40149 \\
\hline PROTEACEAE & & & & \\
\hline
\end{tabular}


Tabela 1. Continuação...

\begin{tabular}{|c|c|c|c|c|}
\hline Família/Espécie & Nome popular & Hábito & Fisionomia & SPSF \\
\hline Roupala montana Aubl. & carne-de-vaca & Árvore & $\mathrm{CD}$ & \\
\hline Colubrina glandulosa Perkins & saraguagi-vermelho & Árvore & FESM & \\
\hline \multicolumn{5}{|l|}{ RHAMNACEAE } \\
\hline Rhamnus sphaerosperma $\mathrm{Sw}$. & canjica & Arbusto & $\mathrm{C}, \mathrm{CD}, \mathrm{CR}$ & 39741,41243 \\
\hline \multicolumn{5}{|l|}{ ROSACEAE } \\
\hline Prunus myrtifolia L. & pessegueiro-bravo & Árvore & $\mathrm{CD}$ & \\
\hline Rubus brasiliensis Mart. & amora-branca & Arbusto & $\mathrm{CD}, \mathrm{CR}$ & 39708,40458 \\
\hline \multicolumn{5}{|l|}{ RUBIACEAE } \\
\hline Alibertia myrciifolia Spruce ex K.Schum. & marmelinho & Arbusto & FESM & \\
\hline Amaioua intermedia Mart. & café-do-mato & Árvore & $\mathrm{C}$ & \\
\hline Coccocypselum glabrifolium Standl. & & Erva & $\mathrm{C}$ & 39715 \\
\hline Coccocypselum lanceolatum Pers. & piririca & Erva & $\mathrm{C}, \mathrm{FESM} *$ & 39716,41135 \\
\hline Cordiera concolor (Cham.) Kuntze & marmelada & Arbusto & $\mathrm{C}, \mathrm{CD}, \mathrm{CR}, \mathrm{FESA}$ & 39565,40151 \\
\hline Declieuxia cordigera Mart. \& Zucc. & & Erva & $\mathrm{CR}$ & 39704 \\
\hline Diodella radula (Willd. ex Roem. \& Schult.) Delprete & erva-de-lagarto & Erva & CR & 41530 \\
\hline Guettarda viburnoides Cham. \& Schltdl. & jangada & Árvore & $\mathrm{CD}$ & 40147 \\
\hline Ixora venulosa Benth. & ixora & Arbusto & FESM & \\
\hline Manettia cordifolia Mart. & cipó-de-santo-antonio & Liana & FESM* & 40179,41134 \\
\hline Margaritopsis cephalantha (Müll. Arg.) C.M.Taylor & cravo-selvagem & Arbusto & $\mathrm{C}$ & \\
\hline Palicourea croceoides Ham. & & Erva & $\mathrm{C}, \mathrm{FESA}$ & 39690,40143 \\
\hline Palicourea rigida H.B.K. & douradinha & Arbusto & $\mathrm{CD}$ & 41121,41199 \\
\hline Posoqueria acutifolia Mart. & baga-de-macaco & Árvore & FESM* & 40174 \\
\hline Psychotria cf. carthagenensis Jacq. & erva-de-gralha & Arbusto & FESM* & 41145 \\
\hline Psychotria leiocarpa Cham. \& Schltdl. & grandiúva-d'anta & Arbusto & C, FESM & 40510,41522 \\
\hline Psychotria vellosiana Benth. & $\begin{array}{l}\text { erva-de-rato-de-folha- } \\
\text { estreita }\end{array}$ & Árvore & $\mathrm{C}$ & 39756,41090 \\
\hline Randia armata (Sw.) DC. & fruto-de-jacaré & Arbusto & FESM & \\
\hline Rudgea jasminoides (Cham.) Müll.Arg. & rudgea & Erva & $\mathrm{C}$ & 41155 \\
\hline \multicolumn{5}{|l|}{ RUTACEAE } \\
\hline Esenbeckia grandiflora Mart. & pau-de-cotia & Árvore & FESM* & 41212 \\
\hline Helietta apiculata Benth. & amarelinho & Árvore & $\mathrm{CD}, \mathrm{FESM}$ & 41099,41510 \\
\hline \multicolumn{5}{|l|}{ SALICACEAE } \\
\hline Casearia lasiophylla Eichl. & cambroé & Árvore & $\mathrm{C}, \mathrm{CD}$ & \\
\hline Casearia obliqua Spreng. & guaçatonga & Árvore & FESM & \\
\hline Casearia sylvestris Sw. & guaçatonga & Árvore & FESA & 40506 \\
\hline \multicolumn{5}{|l|}{ SANTALACEAE } \\
\hline Phoradendron craspedophyllum Enchl. & erva-de-passarinho & Hemiparasita & FESM* & 41143 \\
\hline \multicolumn{5}{|l|}{ SAPINDACEAE } \\
\hline Allophylus semidentatus (Miq.) Radlk. & camboatã & Árvore & FESM & 41509 \\
\hline Cupania vernalis Cambess. & arco-de-peneira & Árvore & $\mathrm{C}, \mathrm{CD}$ & 39754,40459 \\
\hline Cupania zanthoxyloides Cambess. & cupania-veludo & Árvore & $\mathrm{C}$ & 41154 \\
\hline Matayba elaeagnoides Radlk. & cuvantã & Árvore & $\mathrm{CD}$ & \\
\hline Serjania acoma Radlk. & & Liana & $\mathrm{C}$ & 39722 \\
\hline Serjania erecta Radlk. & cipó-de-timbó & Liana & $\mathrm{CD}, \mathrm{CR}$ & 39703,41543 \\
\hline Serjania gracilis Radlk & timbó & Liana & $\mathrm{CD}$ & 40171 \\
\hline Serjania meridionalis Cambess. & timbó & Liana & $\mathrm{C}$ & 39685 \\
\hline \multicolumn{5}{|l|}{ SAPOTACEAE } \\
\hline Chrysophyllum inornatum Mart. & aleixo & Árvore & $\mathrm{CD}$ & \\
\hline Chrysophyllum marginatum (Hook. \& Arn.) Radlk. & aguaí & Árvore & $\mathrm{C}, \mathrm{FESM} *$ & 39717 \\
\hline Pouteria gardneri (Mart. \& Miq.) Baehni & sapoti-vermelho & Árvore & FESM & \\
\hline Pradosia brevipes T.D.Penn. & fruta-de-tatu & Arbusto & CLU, CD & 41119 \\
\hline
\end{tabular}


Cielo-Filho, R. et al.

Tabela 1. Continuação...

\begin{tabular}{|c|c|c|c|c|}
\hline Família/Espécie & Nome popular & Hábito & Fisionomia & SPSF \\
\hline \multicolumn{5}{|l|}{ SCHIZAEACEAE } \\
\hline Anemia ferruginea Kunth & avenca-docampo & Erva & $\mathrm{CD}$ & 40280 \\
\hline Anemia phyllitidis (L.) Sw. & avenca-de-cacho & Epífita & $\mathrm{CD}$ & 40291 \\
\hline \multicolumn{5}{|l|}{ SMILACACEAE } \\
\hline Smilax elastica Griseb. & japecanga & Liana & $\mathrm{C}, \mathrm{CD}, \mathrm{CR}, \mathrm{FESA}$ & 39705,40463 \\
\hline Smilax fluminensis Steud. & japecanga & Liana & $\mathrm{C}, \mathrm{CD}$ & 39725,40461 \\
\hline \multicolumn{5}{|l|}{ SOLANACEAE } \\
\hline Calibrachoa micrantha Stehmann \& Semir & petunia & Erva & CLU, CR & 39599,39680 \\
\hline Cestrum intermedium Sendtn. & coerana-preta & Arbusto & FESA & 40132 \\
\hline Dyssochroma viridiflora (Sims) Miers & solandra & Árvore & $\mathrm{CD}$ & 41113 \\
\hline Solandra grandiflora $\mathrm{Sw}$ & copo-de-ouro & Arbusto & $\mathrm{C}$ & \\
\hline Solanum campaniforme Roem \& Schult. & joá -manso & Árvore & $\mathrm{CD}$ & 41156 \\
\hline Solanum corymbiflorum (Sendtn.) Bohs & coerana-amarela & Arbusto & $\mathrm{CD}, \mathrm{FESA}$ & 39846,40116 \\
\hline Solanum gemellum Mart. ex. Sendtn. & juá-velame & Arbusto & FESM & 41518 \\
\hline Solanum leucodendron Sendtn. & capoeira-branca & Árvore & FESM & 41519 \\
\hline Solanum lycocarpum A.St.-Hil. & fruta-de-lobo & Arbusto & $\mathrm{CD}, \mathrm{CR}$ & 39695,41250 \\
\hline Solanum sanctaecatharinae Dunal & joá-manso & Árvore & $\mathrm{C}$ & \\
\hline Solanum variabile Mart. & jurubeba-velame & Arbusto & $\mathrm{CD}$ & 41550 \\
\hline STYRACACEAE & estoraque-do-campo & & & \\
\hline Styrax camporum Pohl & estoraque & Árvore & CLU, C, CD, CR & 39571,41152 \\
\hline Styrax ferrugineus Nees \& Mart. & estoraque & Árvore & FESM & 41520 \\
\hline Styrax longiflorum A.DC. & estoraque & Árvore & $\mathrm{C}$ & \\
\hline Styrax pohlii A.DC. & estoraque & Árvore & $\mathrm{C}$ & \\
\hline \multicolumn{5}{|l|}{ SYMPLOCACEAE } \\
\hline Symplocos lanceolata A.DC. & capororoca-falsa & Árvore & $\mathrm{CR}$ & \\
\hline Symplocos pubescens Klotzsch ex Benth. & sete-sangrias & Árvore & $\mathrm{CD}, \mathrm{CR}$ & 39584,39632 \\
\hline Symplocos tenuifolia Brand. & cangalha & Árvore & $\mathrm{C}, \mathrm{CR}, \mathrm{FESM} *$ & 39682,41241 \\
\hline \multicolumn{5}{|l|}{ THYMELAEACEAE } \\
\hline Daphnopsis brasiliensis Mart. & embira-branca & Árvore & FESM & 41507 \\
\hline Daphnopsis fasciculata (Meisn.) Nevling & embira & Árvore & FESM & \\
\hline Daphnopsis utilis Warm. & embira-branca & Árvore & $\mathrm{C}$ & 39709 \\
\hline \multicolumn{5}{|l|}{ URTICACEAE } \\
\hline Cecropia pachystachya Trécul & embaúba-branca & Árvore & $\mathrm{CD}$ & \\
\hline \multicolumn{5}{|l|}{ VERBENACEAE } \\
\hline Lantana fucata Lindl. & lantana-roxa & Arbusto & $\mathrm{CD}$ & \\
\hline Lippia brasiliensis (Link) T.Silva & cambará & Erva & FESM & 41516 \\
\hline Lippia lupulina Cham. & rosa-do-campo & Erva & $\mathrm{CD}, \mathrm{CR}$ & 41475,41536 \\
\hline Lippia velutina Schauer & & Arbusto & $\mathrm{CR}$ & 39764 \\
\hline Verbena rigida Spreng & verbena-perene & Erva & FESA & 41559 \\
\hline \multicolumn{5}{|l|}{ VIOLACEAE } \\
\hline Anchietea pyrifolia A. St.-Hil. & suma-roxa & Liana & FESM* & 41148 \\
\hline \multicolumn{5}{|l|}{ VOCHYSIACEAE } \\
\hline Callisthene castellanosi H.F.Martins & & Árvore & $\mathrm{CR}, \mathrm{FESM} *$ & 39743,40184 \\
\hline Qualea cordata (Mart.) Spreng. & carvãozinho & Árvore & $\mathrm{C}, \mathrm{CD}$ & 39771,39807 \\
\hline Qualea grandiflora Mart. & pau-terra & Árvore & $\mathrm{C}$ & 39622 \\
\hline Vochysia tucanorum Mart. & cinzeiro & Árvore & CR, FESM*, FESM & 39614,41514 \\
\hline \multicolumn{5}{|l|}{ WINTERACEAE } \\
\hline Drimys brasiliensis Miers & casca-d'anta & Árvore & $\begin{array}{c}\mathrm{CD}, \mathrm{CR}, \mathrm{FESM}^{*}, \\
\text { FESA }\end{array}$ & 39815,41556 \\
\hline \multicolumn{5}{|l|}{ XYRIDACEAE } \\
\hline Xyris savanensis Miq. & & Erva & $\mathrm{CD}$ & 41198 \\
\hline
\end{tabular}


Piptocarpha rotundifolia (Less.) Baker, Dimorphandra mollis Benth., Couepia grandiflora (Mart.) Benth, Eriotheca gracilipes (Schum.) A. Robyns, Xylopia aromatica Lam., Eugenia aurata O. Berg e Qualea multiflora Mart. Em relação ao conjunto das 17 espécies consideradas mais frequentes nos cerrados paulistas apontadas por Siqueira \& Durigan (2007), estão ausentes na EEcI D. mollis, Miconia stenostachya DC. e Tocoyena formosa (Cham. \& Schltdl.) K. Schum..

\section{Incidência de espécies}

A comparação entre os dados de incidência de espécies gerados no presente estudo com dados derivados de modelos de distribuição geográfica revelou que Annona dioica A.St.-Hil., Brosimum gaudichaudii Trécul, Duguetia furfuracea (A.St.-Hil.) Saff., Caryocar brasiliense Cambess., Anadenanthera peregrina var. falcata (Benth.) Altschul e Schefflera vinosa (Cham. \& Schltdl.) Frodin \& Fiaschi não foram previstas para a região da área de estudo (Siqueira \& Durigan 2007), no entanto, foram encontradas no presente

Tabela 2. Similaridade florística (Sorensen) entre fisionomias de cerrado (s.l.) e campestre úmida na Estação Ecológica de Itapeva.

Table 2. Floristic similarity (Sorensen) among cerrado (s.l.) and Swamp Grassland physiognomies in the Ecological Station of Itapeva.

\begin{tabular}{lccc}
\hline & Cerradão & Cerrado denso & Cerrado ralo \\
\hline Cerrado denso & 0,31 & & \\
Cerrado ralo & 0,26 & 0,38 & \\
Campestre úmida & 0,18 & 0,30 & 0,27 \\
\hline
\end{tabular}

levantamento. As duas últimas são, inclusive, visualmente bastante abundantes na Estação. Outras sete espécies com distribuição espacial modelada, e encontradas em Itapeva neste estudo, foram previstas para a região aparentemente por apenas um dos modelos gerados pelo algoritmo genético (Siqueira \& Durigan 2007).

\section{Discussão}

Considerando a flora da EEcI como um todo, observa-se que a riqueza estimada de espécies (437) aproxima-se da obtida por Durigan et al. (1999), que registraram 486 espécies em inventário semelhante na Estação Ecológica de Assis, SP. Outros levantamentos amplos que consideraram a variedade de fisionomias e formas de vida em áreas de Cerrado reportaram a ocorrência de 458 espécies no Parque Estadual do cerrado, em Jaguariaíva, PR (Linsingen et al. 2006) e 314 espécies na Estação Ecológica de Santa Bárbara, SP (Meira-Neto et al. 2007). Embora devam ser consideradas as diferenças de tamanho das áreas de vegetação natural estudadas, as variações no esforço amostral e nos critérios de inclusão, além de particularidades de cada localidade, evidencia-se a riqueza de espécies relativamente elevada para a EEcI, sendo causas prováveis: a sua condição de área protegida na forma de Unidade de Conservação, resultando em ausência de pastoreio e de incêndios recentes; a sua localização em uma região de interface entre várias formações vegetais que ocorrem no estado de São Paulo (Kronka et al. 2005); a variedade fisionômica; e as particularidades climáticas da região.

Restringindo a análise à flora das fisionomias que ocorrem no cerrado (s.l.), verifica-se que a riqueza estimada (346) encontra-se no intervalo de variação de outros estudos realizados no estado de

Tabela 3. Espécies ameaçadas de extinção registradas na Estação Ecológica de Itapeva, segundo as listas da União Internacional para a Conservação da Natureza (IUCN), Fundação Biodiversitas (FB), Ministério do Meio Ambiente (MMA) e Secretaria do Meio Ambiente do estado de São Paulo (SMA-SP). CR, Em Perigo Crítico; EN, Em Perigo; VU, Vulnerável. As espécies ameaçadas de acordo com o MMA estão indicadas por "1".

Table 3. Threatened species recorded in the Ecological Station of Itapeva according to the lists of the International Union for Conservation of Nature (IUCN), Biodiversitas Foundation (FB), Brazilian Environmental Agency (MMA) and Environmental Bureau of the São Paulo State (SMA-SP). CR, Critically Endangered; EN, Endangered; VU, Vulnerable. Threatened species according to MMA are indicated by " 1 ".

\begin{tabular}{|c|c|c|c|c|c|}
\hline Família/Espécie & IUCN & FB & MMA & SMA-SP & Tipo de ameaça \\
\hline \multicolumn{6}{|l|}{ Apiaceae } \\
\hline Eryngium eriophorum & & & 0 & EN & $\begin{array}{l}\text { Distribuição geográfica restrita, ocorrência desconhecida } \\
\text { em unidade de conservação e ocorrência em um único } \\
\text { tipo de formação vegetal. }\end{array}$ \\
\hline
\end{tabular}

\section{Araucariaceae}

$\begin{array}{llll}\text { Araucaria angustifolia } & \text { CR } & \text { EN } & 1\end{array}$ VU Espécie com histórico de exploração intensiva.

\section{Asteraceae}

Calea cymosa

Neocabreria malacophylla

0

Lauraceae

Ocotea odorifera

VU

Malvaceae

Abutilon costicalyx

\section{Meliaceae}

Cedrela odorata

VU

0

Sapindaceae

Allophylus semidentatus
0
$0 \quad \mathrm{EN}$

EN

VU tipo de formação vegetal.

Distribuição geográfica restrita, ocorrência desconhecida em unidade de conservação e ocorrência em um único Distribuição geográfica restrita e ocorrência desconhecida em unidade de conservação.

Baixa densidade populacional e exploração.

$0 \quad$ EN

EN Distribuição geográfica restrita, ocorrência desconhecida em unidade de conservação e ocorrência em um único tipo de formação vegetal.

Desmatamento e exploração.

VU Distribuição geográfica restrita e ocorrência exclusiva em unidade de conservação. 
São Paulo: entre 75 e 443 espécies (Batalha \& Mantovani 2000, Weiser \& Godoy 2001, Durigan et al. 2002, Fidelis \& Godoy 2003, Meira-Neto et al. 2007, Ishara et al. 2008, Sasaki \& Melo-Silva 2008). Os fatores que possivelmente contribuem para essa elevada riqueza são os mesmos considerados acima com respeito à flora da Estação como um todo. Linsingen et al. (2006) também mostraram uma elevada riqueza de espécies de plantas vasculares em área de cerrado (s.l.) localizada no limite meridional de distribuição do Bioma e comentaram que a riqueza poderia ser maior, não fosse o rigoroso inverno restringindo a ocorrência de algumas espécies. Portanto, mesmo com as possíveis restrições impostas pelo clima, os remanescentes localizados no extremo sul do Bioma apresentam riqueza comparável à de remanescentes mais próximos à sua área core.

Levantamentos em cerrado (s.l.) apontaram as famílias Asteraceae, Myrtaceae, Fabaceae, Malpighiaceae, Bignoniaceae, Melastomataceae, Rubiaceae, Vochysiaceae, Poaceae e Annonaceae como as mais ricas (Durigan et al. 1999, Batalha \& Mantovani 2000, Weiser \& Godoy 2001, Durigan et al. 2002, Fidelis \& Godoy 2003, Meira-Neto et al. 2007, Ishara et al. 2008, Sasaki e Melo-Silva 2008). Das famílias supracitadas, a maioria é bem representada em número de espécies na EEcI. As famílias mais ricas do componente não-arbóreo da Estação foram mencionadas entre as mais representativas nos levantamentos de cerrado (s.l.) que consideraram esse componente individualmente (Christianini \& Cavassan 1998, Batalha \& Mantovani 2001, Weiser \& Godoy 2001, Tannus \& Assis 2004, Ishara et al. 2008, Rossatto et al. 2008). Da mesma forma, a distribuição da riqueza de espécies arbóreas entre as famílias concorda em geral com as informações da literatura sobre o cerrado (s.l.) no Brasil (Oliveira-Filho \& Ratter 2002) e no estado de São Paulo (Cavassan 2002). Por outro lado, o destaque mostrado por Lauraceae no cerrado (s.l.) da EEcI pode ser uma peculiaridade regional em função da importância dessa família para florestas da região Sul do país (Souza \& Lorenzi 2008).

O número de espécies arbóreas (133) superou o número de espécies herbáceas (100) no cerrado (s.l.) da EEcI, assim como a área ocupada por cerradão e cerrado denso (87 ha) supera consideravelmente a área ocupada por cerrado ralo, campo sujo úmido e campo limpo úmido (5,5 ha). De maneira geral, a flora herbácea do cerrado é considerada mais rica do que a flora arbórea (Goodland \& Ferri 1979). Em sua análise sobre as comunidades herbáceas do Cerrado, Filgueiras (2002) informa que a razão entre ervas e árvores varia de 3:1 (Felfili et al. 1994) a 4,5:1 (Mendonça et al. 1998). Por outro lado, dados apresentados por Goodland \& Ferri (1979), mostram que o número de espécies herbáceas diminui e o número de arbóreas aumenta das fisionomias mais abertas para as mais fechadas e que, no cerradão, o número de espécies arbóreas supera o número de herbáceas. No presente trabalho, o maior número de espécies arbóreas relativamente ao de herbáceas pode ser explicado, em parte, pelo predomínio das fisionomias cerradão e cerrado denso. Resultado semelhante foi encontrado no cerrado (s.l.) da Estação Ecológica de Santa Bárbara (Meira-Neto et al. 2007), onde o número de espécies arbóreas (149) superou o número de herbáceas (119) e a área ocupada por cerradão, cerrado denso e cerrado típico (1.819 ha) é maior que a área ocupada por campo cerrado e campo úmido (435 ha) (Durigan et al. dados não publicados). Por outro lado, no Parque Estadual do Cerrado, onde não foram registradas as fisionomias cerradão e cerrado denso, o número de espécies de árvores (27) foi menor que o número de ervas (81) e a área ocupada por formações campestres (188 ha) superou a área ocupada por cerrado típico (83 ha) (Linsingen et al. 2006). Portanto, a relação entre o número de árvores e ervas em dada localidade depende da representatividade das diferentes fisionomias de cerrado (s.l.) que aí ocorrem, embora uma relação entre 3:1 e 4,5:1 possa se manter para a flora do Cerrado como um todo (Filgueiras 2002).

A inclusão da fisionomia campestre úmida na delimitação de cerrado (s.l.) adotada neste trabalho foi suportada pelos dados de similaridade florística (ver critérios em Material e Métodos). O mesmo tratamento pode ser encontrado em Meira-Neto et al. (2007) para o campo limpo úmido. Por outro lado, Batalha (1997), Tannus \& Assis (2004) e Linsingen et al. (2006) não consideraram o campo limpo úmido como fisionomia de cerrado (s.l.). Batalha (1997) reportou similaridade florística (Sorensen) de 0,41 entre o campo úmido e campo cerrado. Os dados de Tannus \& Assis (2004) permitem calcular uma similaridade de 0,05 entre campo limpo úmido e campo sujo de interflúvio. A maior intensidade de perturbação poderia ser responsável pela diferença de similaridade entre fisionomias campestres úmidas e aquelas de cerrado (s.l.) de interflúvio reportadas nesses dois estudos, resultando na ocorrência generalizada de espécies ruderais em diferentes fisionomias. Porém, Tannus \& Assis (2004) encontraram 60 espécies ruderais em um total de 284 e apenas duas ocorreram simultaneamente nas duas fisionomias estudadas pelos autores. Verifica-se, portanto, que a similaridade florística entre fisionomias campestres úmidas e fisionomias de cerrado (s.l.) no conceito de Coutinho (1978) pode variar bastante entre localidades, podendo atingir níveis que justificariam o tratamento adotado para a vegetação da EEcI.

Dentre os principais fatores de ameaça de extinção verificados, a distribuição geográfica restrita e a ocorrência desconhecida em unidade de conservação se destacam. O primeiro fator é uma característica natural da espécie, que a torna mais propensa à extinção em virtude do processo histórico de eliminação de áreas de Cerrado no estado de São Paulo (Kronka et al. 2005). O segundo fator é mais dinâmico, podendo sua aplicação ser alterada em função do avanço do conhecimento sobre a biodiversidade. Assim, as quatro espécies consideradas ameaçadas em função de ocorrência desconhecida em unidade de conservação não mais poderiam ser enquadradas nas categorias de ameaça definidas em Souza et al. (2007). A contribuição da EEcI para a conservação dessas espécies fica evidente com essa mudança de nível de ameaça. A proteção dessas espécies poderá ser enfatizada em programas de educação ambiental e na captação de recursos para o manejo da UC.

A espécie com nível de ameaça mais preocupante é Araucaria angustifolia (Bert.) Kuntze, não apenas em função das categorias de ameaça atribuídas nas diferentes listas, mas também devido à sua presença em todas as listas, ou seja, nas escalas geográficas estadual, nacional e mundial. Apenas um indivíduo da espécie foi observado na EEcI, na Floresta Estacional Semidecidual Montana. De acordo com Garcia (2002) indivíduos isolados da espécie podem ser encontrados na Floresta Estacional Semidecidual, entre as faces ocidental das serras do Mar e de Paranapiacaba e a Depressão Periférica. A importância da EEcI para a conservação dessa espécie certamente é menor do que a da Estação Experimental de Itapeva que lhe é contígua e abriga 324 ha de remanescentes de Floresta Estacional Semidecidual Montana (Instituto Florestal 2010) com ocorrência de indivíduos de araucária (Souza et al. in prep.), enquanto a EEcI apresenta apenas 6,92 ha ocupados por essa fisionomia. A Estação Experimental abriga também remanescentes de cerrado (s.l.). Portanto, a conservação da vegetação natural na Estação Experimental de Itapeva pode contribuir para a conservação das espécies ameaçadas presentes na EEcI.

Dentre as espécies consideradas típicas do cerrado (s.l.) paulista (Bridgewater et al. 2004, Siqueira \& Durigan 2007), mas que estiveram ausentes na EEcI, Scaramuzza (2006) citou Miconia stenostachya e Piptocarpha rotundifolia para os campos de Itararé, ao sul de Itapeva. Linsingen et al. (2006) e Ritter et al. (2010) 
citaram Couepia grandiflora, Qualea multiflora e Eriotheca gracilipes para áreas de cerrado (s.l.) no Paraná. É possível que as demais espécies - Dimorphandra mollis, Xylopia aromatica, Eugenia aurata e Tocoyena formosa - sejam encontradas em futuros levantamentos em porções tão ou mais meridionais do que a área de estudo, mas também é provável que essas espécies apresentem restrições ecológicas que comprometam seu desenvolvimento ou sobrevivência no limite meridional do bioma Cerrado. Corroborando essa afirmação, Ritter et al. (2010) compilaram uma lista geral para 30 remanescentes de cerrado (s.l.) no Paraná, totalizando 1.782 espécies, mas não encontraram D. mollis, X. aromatica, E. aurata e T. formosa. É provável que o limite meridional de distribuição geográfica dessas espécies encontre-se em latitudes inferiores à da área de estudo, sendo o seu plantio na região desaconselhável.

Dentre as possíveis restrições ecológicas, o dano aos tecidos vegetais provocados por geadas é enfatizado na literatura (Leitão-Filho 1992, Silberbauer-Gottsberger et al. 1977). A ocorrência de geadas não é fato incomum no limite meridional do cerrado (Coutinho 2002), algumas inclusive se destacaram historicamente por sua intensidade e pelos prejuízos econômicos causados, tais como as geadas de 1975 e 1994. Em função da posição latitudinal, verifica-se diminuição da temperatura e aumento na frequência de geadas na região de Itapeva em comparação com o restante do estado de São Paulo (Eiten 1970). Em relação à sensibilidade das espécies lenhosas do cerrado (s.l.), as informações são escassas, porém é sabido que Miconia albicans e Xylopia aromatica foram mencionadas como as mais prejudicadas em Botucatu, após a geada de 1975 (Silberbauer-Gottsberger et al. 1977), e também foram citadas como espécies susceptíveis após a geada de 1994 em Agudos (Bertoncini 1996). X. aromatica é uma das espécies típicas ausentes na EEcI, mas $M$. albicans é visualmente bastante conspícua, sugerindo que a susceptibilidade à geadas não deve ser o único fator limitador da distribuição geográfica das espécies de cerrado (s.l.) em climas mais frios.

A região de Itapeva apresenta duas peculiaridades que a credenciam como prioritária para a realização de estudos florísticos no Cerrado: a posição no limite meridional de distribuição do Bioma (Brasil 2008a) e a ausência de déficit hídrico (Instituto Brasileiro de Geografia e Estatística 1990). Esta última característica destoa das condições predominantes na área core do Cerrado, que apresenta forte estacionalidade climática e déficit hídrico (Silva et al. 2008), e mesmo do restante da área ocupada pelo Cerrado no estado de São Paulo (Eiten 1970). A presença de Cerrado em uma região sem déficit hídrico pode ser considerada como relictual, tendo em vista as flutuações climáticas do período Quaternário, que possibilitaram a expansão do Cerrado sobre áreas florestais (Pessenda et al. 2009). Após o término do período seco, mesmo em regiões com forte estacionalidade climática, as florestas teriam avançado sobre o Cerrado, mas essa substituição teria sido prejudicada por incêndios provocados pelo homem desde o meio Holoceno (Oliveira-Filho \& Ratter 1995). Esses autores argumentam que a ocorrência de Florestas Estacionais Semideciduais sobre solos secos e pobres na região do Cerrado sugere que as condições climáticas atuais são favoráveis ao estabelecimento de florestas na maior parte do Bioma. Se tal argumento é válido para a área core do Cerrado, tanto mais o será para a região de Itapeva, devido à ausência de déficit hídrico. As mesmas considerações sobre o clima atual e flutuações climáticas do Holoceno sugerem que a ocorrência de Cerrado no Paraná também seria relictual (Straube 1998).

Algumas espécies encontradas neste estudo, embora consideradas características de Cerrado em outras regiões do estado de São Paulo, não tiveram sua ocorrência prevista para a região de Itapeva por modelagem de distribuição geográfica em escala estadual (Siqueira \& Durigan 2007). Provavelmente, contribuíram para esses resultados as peculiaridades geográfica e climática mencionadas acima, aliadas ao fato de que a amostragem de Siqueira \& Durigan (2007) não incluiu áreas de Cerrado em posição geográfica semelhante ou na mesma zona climática verificada para Itapeva (Instituto Brasileiro de Geografia e Estatística 1990). Uma das principais limitações encontradas no uso de ferramentas de modelagem de distribuição geográfica diz respeito aos problemas de comissão ou de omissão com a diminuição ou ampliação, respectivamente, da escala geográfica de trabalho (Peterjohn 2001). A omissão de algumas espécies para a região de Itapeva pelos modelos apresentados em Siqueira \& Durigan (2007) pode estar relacionada à ampliação da escala para regiões com parâmetros climáticos diferentes daqueles incluídos nos modelos. A inclusão de levantamentos efetuados na região de Itapeva poderá gerar predições mais acuradas tanto para as espécies como para o bioma Cerrado no estado de São Paulo. Por outro lado, é possível questionar a uso de dados florísticos de áreas consideradas relictuais para a geração de modelos preditivos de distribuição geográfica de um bioma e suas espécies, pois, assim, obter-se-iam predições mais relacionadas a fatores históricos do que ecológicos.

\section{Conclusões}

De maneira geral, observa-se que tanto a riqueza em espécies como a distribuição da riqueza entre as famílias não evidenciaram diferenças marcantes entre a flora do cerrado (s.l.) da EEcI e de outras áreas de Cerrado localizadas em regiões mais setentrionais. Contudo, análises em nível de espécie evidenciaram, como uma particularidade da flora da região deste estudo, a ausência de espécies arbóreas consideradas típicas do cerrado (s.l.) paulista, possivelmente em decorrência dos efeitos de geadas e outros fatores climáticos restritivos.

Por outro lado, constatamos na EEcI a presença de espécies não previstas para a região por modelagem de distribuição geográfica, provavelmente em decorrência da não inclusão de levantamentos florísticos realizados na região de Itapeva na base de dados utilizada para gerar os modelos (Siqueira \& Durigan 2007), reforçando a necessidade de ampliação do esforço de coleta em certas regiões do estado de São Paulo, como a bacia hidrográfica do Alto Paranapanema, onde a área de estudo está inserida (Cielo-Filho et al. 2009).

Análises comparativas da similaridade florística entre o cerradão, cerrado denso, cerrado ralo, campo sujo úmido e campo limpo úmido da EEcI, permitiram incluir todas essas fisionomias dentro de uma delimitação de cerrado (s.l.) mais abrangente do que a adotada por Coutinho (1978), que considera apenas vegetação de interflúvio sobre solo bem drenado. Sugerimos que a inclusão de fisionomias úmidas no cerrado (s.l.) deva ser considerada separadamente para cada localidade tendo em vista as relações florísticas entre as fisionomias.

Dentre as oito espécies ameaçadas de extinção na EEcI, quatro poderiam perder esse status se uma reavaliação considerasse sua ocorrência naquela Unidade de Conservação. Contudo, as pequenas dimensões da EEcI enfraquecem a sua importância na conservação das espécies ameaçadas, o que demonstra a necessidade de ampliação de seus limites territoriais bem como de conservação de remanescentes de vegetação natural situados na contígua Estação Experimental de Itapeva. Tal constatação é particularmente pertinente para a conservação de Araucaria angustifolia, tendo em vista a ocorrência dessa espécie em áreas florestais adjacentes à EEcI.

\section{Agradecimentos}

Somos gratos aos Pesquisadores do Instituto Florestal Ananias de Almeida Pontinha e Geraldo Antonio Daher Corrêa Franco pelo apoio logístico e auxílio na identificação de espécies, respectivamente; ao Técnico de Herbário Ernane Lino da Silva, pelo apoio no 
processamento e montagem do material botânico; à Pesquisadora Marina Mitsue Kanashiro pela elaboração da figura e fornecimento dos dados correspondentes; à Betânia Monteiro Cielo, pela revisão gramatical do manuscrito; ao Sr. Pedro, funcionário da Estação Experimental de Itapeva, pelo auxilio em campo. Agradecemos especialmente aos seguintes taxonomistas especialistas: Anderson Luiz dos Santos, André dos Santos Bragança Gil, Carlos Alberto Garcia Santos, Cíntia Kameyama, Cíntia Takeuchi, Fátima Otaviana de Souza-Buturi, Gerleni Lopes Esteves, Gustavo Shinizu, Inês Cordeiro, Jefferson Prado, João Luiz Mazza Aranha Filho, João Renato Stehmann, Kikyo Yamamoto, Leandro Lacerda Giacomin, Lidyanne Yuriko S. Aona, Lucia Rossi, Luiz Carlos Bernacci, Marcelo Monge Egea, Maria Ana Farinaccio, Maria Leonor D'El Rei Souza, Marie Sugiyama, Mizué Kirizawa, Paulo José Fernandes Guimarães, Paulo Takeo Sano, Rafael Louzada, Renata Sebastiani, Renato Goldenberg, Renato Mello-Silva, Rosângela Simão-Bianchini, Sergio Rokmaniuc Neto e Wellington Forster.

\section{Referências Bibliográficas}

AGUIAR, L.M.S. \& CAMARGO, A.J.A. 2004. Cerrado: ecologia e caracterização. Embrapa, Brasília.

ALMEIDA, R.S., SOUZA, S.C.P.M., BAITELLO, J.B., PASTORE, J.A., AGUIAR, O.T., KANASHIRO, M.M., MATTOS, I.F.A., LIMA, C.R. \& CIELO-FILHO, R. 2010. campo sujo úmido: Fisionomia de cerrado ameaçada pela contaminação biológica de Pinus elliottii Engelm. na Estação Ecológica de Itapeva, Estado de São Paulo. Rev. Inst. Florest. 22(1):71-91.

ANGIOSPERM PHYLOGENY GROUP - APG. 2009. An update of the Angiosperm Phylogeny Group classification for the orders and families of flowering plants: APG III. Bot. J. Linn. Soc. 161:105-121. http://dx.doi. org/10.1111/j.1095-8339.2009.00996.x

ARRUDA, M.B., PROENÇA, C.E.B., RODRIGUES, S.C., CAMPOS, R.N., MARTINS, R.C. \& MARTINS, E.S. 2008. Ecorregiões, unidades de conservação e representatividade ecológica do bioma cerrado. In Cerrado: ecologia e flora (S.M. Sano, S.P. Almeida \& J.F. Ribeiro, orgs.). Embrapa cerrados, Brasília, p.229-272.

BATALHA, M.A. 1997. Análise da vegetação da ARIE cerrado Pé-de-Gigante (Santa Rita do Passa Quatro, SP). Dissertação de Mestrado, Universidade de São Paulo, São Paulo.

BATALHA, M.A. 2011. O cerrado não é um bioma. Biota Neotrop. 11(1): http://www.biotaneotropica.org.br/v11n1/pt/abstract?inventory+ bn00111012011.

BATALHA, M.A. \& MANTOVANI, W. 2000. Reproductive phenological patterns of cerrado plant species at the Pé-de-Gigante Reserve (Santa Rita do Passa Quatro, SP, Brazil): a comparison between the herbaceous and woody floras. Rev. Bras. Biol. 60(1):129-145. PMid:10838932. http:// dx.doi.org/10.1590/S0034-71082000000100016

BATALHA, M.A. \& MANTOVANI, W. 2001. Floristic composition of the cerrado in the Pé-de-Gigante Reserve (Santa Rita do Passa Quatro, Southeastern Brazil). Acta Bot. Bras. 15(3):289-304. http://dx.doi. org/10.1590/S0102-33062001000300001

BERTONCINI, A.P. 1996. Composição floristica e estrutura fitossociológica de uma área de cerrado no município de Agudos, SP. Dissertação de Mestrado, Universidade Estadual Paulista, Botucatu.

BRASIL. 2008a. Monitoramento do desmatamento dos biomas brasileiros por satélite: monitoramento do bioma cerrado 2002 a 2008. Ministério do Meio Ambiente, Brasília, p.68.

BRASIL. Ministério do Meio Ambiente. 2008b. Instrução Normativa nº 06, de 26 de setembro de 2008. Diário Oficial da República Federativa do Brasil, Brasília, DF, set. 2008. http://www.mma.gov.br (último acesso em 05/12/2008).
BRIDGEWATER, S., RATTER, J.A. \& RIBEIRO, J.F. 2004. Biogeographic patterns, b-diversity and dominance in the cerrado biome of Brazil. Biodivers. Conserv. 13:2295-2318. http://dx.doi.org/10.1023/ B:BIOC.0000047903.37608.4c

CAVASSAN, O. 2002. O cerrado no Estado de São Paulo. In Eugen Warming e o cerrado brasileiro: um século depois (A.L. Klein, org.). Editora UNESP, São Paulo, p.93-106.

CHRISTIANINI, S.R. \& CAVASSAN, O. 1998. Oestrato herbáceo-subarbustivo de um fragmento de cerradão em Bauru-SP. Salusvita 17:9-16.

CIELO-FILHO, R., BAITELLO, J.B., PASTORE, J.A., AGUIAR, O.T., SOUZA, S.C.P.M., TONIATO, M.T.Z., LIMA, C.R. \& RIBEIRO, A.P. 2009. Ampliando a densidade de coletas botânicas na região da bacia hidrográfica do Alto Paranapanema: Caracterização florística da Floresta Estadual e da Estação Ecológica de Paranapanema. Biota Neotrop. 9(3): http://www.biotaneotropica.org.br/v9n3/en/abstract?inve ntory+bn02009032009 (ultimo acesso em 29/11/2010).

CIELO-FILHO, R., AGUIAR, O.T., BAITELLO, J.B., PASTORE, J.A., SOUZA, S.C.P.M., LIMA, C.R., KANASHIRO, M.M., MATTOS, I.F.A., DURIGAN, G., IVANAUSKAS, N.M., BERTANI, D.F., SOUZA, F.M., TONIATO, M.T.Z., FRANCO, G.A.D.C., RIBEIRO, A.P., ALMEIDA, R.S., COSTA, N.O. \& CARMONA, M. 2011. A vegetação da Estação Ecológica de Itapeva: subsídios para o Plano de Manejo. IF Sér. Reg. 46:1-82.

COUTINHO, L.M. 1978. O conceito de cerrado. Rev. Bras. Bot. 1(1):17-23.

COUTINHO, L.M. 2002. O bioma do cerrado. In Eugen Warming e o cerrado brasileiro: um século depois (A.L. Klein, org.). Editora UNESP, São Paulo, p.77-91.

COUTINHO, L.M. 2006. O conceito de bioma. Acta Bot. Bras. 20(1):13-23. http://dx.doi.org/10.1590/S0102-33062006000100002

DURIGAN, G., BACIC, M.C., FRANCO, G.A.D.C. \& SIQUEIRA, M.F. 1999. Inventário florístico do cerrado da Estação Ecológica de Assis, SP. Hoehnea 26(2):149-172.

DURIGAN, G., NISHIKAWA, D.L.L., ROCHA, E., SILVEIRA, E.R., PULITANO, F.M., REGALADO, L.B., CARVALHAES, M.A., PARANAGUÁ, P.A. \& RANIERI, V.E.L. 2002. Caracterização de dois estratos da vegetação em uma área de cerrado no município de Brotas, SP, Brasil. Acta bot. bras. 16(3):251-262.

DURIGAN, G., SIQUEIRA, M.F., FRANCO, D.C., BRIDGEWATER, S. \& RATTER, J.A. 2003. The vegetation of priority areas for cerrado conservation in São Paulo State, Brazil. Edinb. J. Bot. 60(2):217-241.

EITEN, G. 1970. A vegetação do Estado de São Paulo. Bol. Inst. Bot. 7:1-147. EITEN, G. 1979. Formas fisionômicas do cerrado. Rev. Bras. Bot. 2:139-148.

FEELEY, K.J., SILMAN, M.R. 2011. The data void in modeling current and future distributions of tropical species. Glob. Change Biol. 17:626-630 http://dx.doi.org/10.1111/j.1365-2486.2010.02239.x

FELFILI, J.M., FILGUEIRAS, T.S., HARIDASAN, M., SILVA JUNIOR, M.C., MENDONÇA, R.C. \& REZENDE, A.V. 1994. Projeto biogeografia do bioma cerrado: vegetação e solos. Cad. Geocienc. 12:75-166.

FIDALGO, O. \& BONONI, V.L.R. 1989. Técnicas de coleta, preservação e herborização de material botânico. Instituto de Botânica, Imprensa Oficial do Estado de São Paulo, São Paulo.

FIDELIS, A.T. \& GODOY, S.A.P. 2003. Estrutura de um cerrado stricto sensu na gleba cerrado Pé-de-Gigante, Santa Rita do Passa Quatro, SP. Acta Bot. Bras. 17(4):531-539. http://dx.doi.org/10.1590/S010233062003000400006

FILGUEIRAS, T.S. 2002. Herbaceous plant communities. In The cerrados of Brazil: Ecology and Natural History of a Neotropical Savanna (P.S. Oliveira \& R.J. Marquis, orgs.). Columbia University Press, New York, p.121-139.

FILGUEIRAS, T.S., NOGUEIRA, P.E., BROCHADO, A.L. \& GUALA II, G.F. 1994. Caminhamento - um método expedito para levantamentos florísticos qualitativos. Cad. Geocienc. 12:39-43. 
FUNDAÇÃO BIODIVERSITAS. Lista oficial de espécies ameaçadas de extinção no Brasil. http://www.biodiversitas.org.br./florabr/grupo3fim. asp (último acesso em 10/12/2008).

GARCIA, R.J.F. 2002. Araucariaceae. In Flora Fanerogâmica do Estado de São Paulo (M.G.L. Wanderley, G.J. Shepherd \& A.M. Giulietti, orgs.). FAPESP/HUCITEC, São Paulo, v.2, p.1-2.

GOODLAND, R. \& FERRI, M.G. 1979. Ecologia do cerrado. Editora da Universidade de São Paulo, São Paulo, p.1-178.

INSTITUTO BRASILEIRO DE GEOGRAFIA E ESTATÍSTICA IBGE. 1990. Diagnóstico. Brasil. A Ocupação do Território e do Meio Ambiente e uma Avaliação da Ocupação do Território. IBGE, Rio de Janeiro.

INTERNATIONAL PLANT NAMES INDEX - IPNI. 2010. http://www. ipni.org/ipni/plantnamesearchpage.do (último acesso em 15/09/2010).

INTERNATIONAL UNION FOR CONSERVATION OF NATURE IUCN. 2001. Red List categories and criteria version. 3.1. IUCN Species Survival Commission, Gland, $35 \mathrm{p}$.

INTERNATIONAL UNION FOR CONSERVATION OF NATURE IUCN. 2010. Lista Vermelha de Espécies Ameaçadas de Extinção da União Internacional para a Conservação da Natureza. http://www. iucnredlist.org (último acesso em 26/08/2010).

INSTITUTO DE PESQUISAS TECNOLÓGICAS - IPT. 2001. Estudos do meio físico para implantação de Distritos Agrícolas Irrigados na zona rural do município de Itapeva, SP. São Paulo. (Relatório Técnico, n.50725).

INSTITUTO FLORESTAL. Sistema de Informações Florestais do Estado de São Paulo - SiFESP. http://www.iflorestal.sp.gov.br/sifesp/ (último acesso em 25/09/2010).

ISHARA, K.L., DÉSTRO, G.F.G., MAIMONI-RODELLA, R.C.S. \& YANAGIZAWA, Y.A.N.P. 2008. Composição florística de remanescente de cerrado sensu stricto em Botucatu, SP. Rev. Bras. Bot. 31(4):575-586. http://dx.doi.org/10.1590/S0100-84042008000400004

JARDIM BOTÂNICO DO RIO DE JANEIRO - JBRJ. 2010. Lista de Espécies da Flora do Brasil. http://floradobrasil.jbrj.gov.br/2010 (último acesso em 29/11/2010).

JUDD, W.S., CAMPBELL, C.S., KELlOG, E.A., STEVENS, P.F. \& DONOGHUE, M.J. 2002. Plant Systematics: A Phylogenetic Approach. Sinauer Associates Inc., Sunderland.

KLINK, C.A. \& MACHADO, R.B. 2005. A conservação do cerrado brasileiro. Megadiversidade 1(1):147-155.

KRONKA, F.J.N., NALON, M.A., MATSUKUMA, C.K., KANASHIRO, M.M., YWANE, M.S.S., PAVAO, M., DURIGAN, G., LIMA, L.M.P.R., GUILLAUMON, J.R., BAITELLO, J.B. \& BARRADAS, A.M.F. 2005. Inventário florestal da vegetação natural do Estado de São Paulo. Secretaria do Meio Ambiente, Instituto Florestal, Imprensa Oficial, São Paulo.

LEGENDRE, P. \& LEGENDRE, L. 1998. Numerical ecology. Elsevier, New York.

LEITÃO-FILHO, H.F. 1992. A flora arbórea dos cerrados do estado de São Paulo. Hoehnea 19(1-2):151-163.

LINSINGEN, L., SONEHARA, J.S., UHLMANN, A. \& CERVI, A. 2006. Composição florística do Parque Estadual de Jaguariaíva, Paraná, Brasil. Acta Biol. Parana 35(3-4):197-232.

MEIRA-NETO, J.A.A., MARTINS, F.R. \& VALENTE, G.E. 2007. Composição florística e espectro biológico na Estação Ecológica de Santa Bárbara, estado de São Paulo, Brasil. Rev. Arvore 31(5):907-922.

MENDONÇA, R.C., FELFILI, J.M., WALTER, B.M.T., SILVA JUNIOR, M.C., REZENDE, A.V., FILGUEIRAS, T.S. \& NOGUEIRA, P.E. 1998. Flora vascular do Cerrado. In Cerrado: Ambiente e Flora. (S.M. Sano \& S.P. de Almeira, orgs.). Empresa Brasileira de Pesquisa Agropecuária, Planaltina, p.289-556.

MISSOURI BOTANICAL GARDEN - MOBOT. http://www.tropicos.org/ (último acesso em 15/09/2010).
MITTERMEIER, R.A., MYERS, N., ROBLES, GIL, P. \& MITTERMEIER, C.G. 1999. Hotspots: earth's biologically richest and most endangered terrestrial ecoregions. CEMEX, Mexico City.

NOVAIS, P.S., ROSSI, M., MATTOS, I.F.A. \& KANASHIRO, M.M. 2009. Os solos da Estação Ecológica de Itapeva: caracterização e mapeamento. IF Sér. Regist. 40:217-222.

OLIVEIRA-FILHO, A.T. \& RATTER, J.A. 1995. A study of the origin of central Brazilian forests by the analysis of plant species distribution patterns. Edinb. J. Bot. 52(2):141-194. http://dx.doi.org/10.1017/ S0960428600000949

OLIVEIRA-FILHO, A.T. \& FONTES, M.A.L. 2000. Patterns of floristic differentiation among Atlantic Forests in Southeastern Brazil and the influence of climate. Biotropica 32:793-810.

OLIVEIRA-FILHO, A.T. \& RATTER, J.A. 2002. Vegetation physiognomies and woody flora of the cerrado Biome. In The cerrados of Brazil: Ecology and Natural History of a Neotropical Savanna (P.S. Oliveira \& R.J. Marquis, orgs). Columbia University Press, New York, p.91-120.

PESSENDA, L.C.R., DE OLIVEIRA, P.E., MOFATTO, M., DE MEDEIROS, V.B., GARCIA, R.J.F., ARAVENA, R., BENDASSOLI, J.A., LEITE, A.Z., SAAD, A.R. \& ETCHEBEHERE, M.L. 2009. The evolution of a tropical rainforest/grassland mosaic in southeastern Brazil since 28,000 14C yr based on carbon isotopes and pollen records. Quaternary Res. 71:437-452. http://dx.doi.org/10.1016/j.yqres.2009.01.008

PETERJOHN, B.G. 2001. Some considerations on the use of ecological models to predict species' geographic distributions. The Condor 103:661-663. http://dx.doi.org/10.1650/0010-5422(2001)103[0661:SCOTUO]2.0.CO;2

PETERSON, A.T. 2001. Predicting species' geographic distributions based on ecological niche modeling. The Condor 103:599-605. http://dx.doi. org/10.1650/0010-5422(2001)103[0599:PSGDBO]2.0.CO;2

RATTER, J.A., BRIDGEWATER, S. \& RIBEIRO, J.F. 2003. Analysis of the floristic composition of the Brazilian cerrado vegetation III: Comparison of the woody vegetation of 376 areas. Edinb. J. Bot. 60:57-109. http:// dx.doi.org/10.1017/S0960428603000064

RIBEIRO, J.F. \& WALTER, B.M.T. 2008. As principais fitofisionomias do bioma cerrado. In cerrado: ecologia e flora (S.M. Sano, S.P. Almeida \& J.F. Ribeiro, orgs.). Embrapa cerrados, Brasília, p.151-212.

RITTER, L.M.O., RIBEIRO, M.C. \& MORO, R.S. 2010. Composição florística e fitofisionomia de remanescentes disjuntos de Cerrado nos Campos Gerais, PR, Brasil - limite austral do bioma. Biota Neotrop. 10(3): http://www.biotaneotropica.org.br/v10n3/en/abstract?inventory+ bn04010032010. (último acesso em 28/03/2011)

RIZZINI, C.T. 1997. Tratado de fitogeografia do Brasil. 2. ed. Âmbito Cultural, Rio de Janeiro.

ROSS, J.L.S. \& MOROZ, I.C. 1997. Mapa Geomorfológico do Estado de São Paulo. Instituto de Pesquisas Tecnológicas e Departamento de Ciências Tecnológicas, USP, FAPESP, São Paulo, v.1-2, Escala 1: 500.000.

ROSSATTO, D.R., TONIATO, M.T.Z. \& DURIGAN, G. 2008. Flora fanerogâmica não-arbórea do cerrado na Estação Ecológica de Assis, Estado de São Paulo. Rev. Bras. Bot. 31(3):409-424. http://dx.doi. org/10.1590/S0100-84042008000300005

SANO, S.M., ALMEIDA S.P. \& RIBEIRO, J.F. 2008. Cerrado: ecologia e flora. Embrapa cerrados, Brasília.

SÃO PAULO (Estado). Resolução SMA n ${ }^{\circ}$ 48, de 21 de setembro de 2004. Lista Oficial das Espécies da Flora do Estado de São Paulo. http://www. ibot.sp.gov.br (último acesso em 10/12/2008).

SASAKI, D. \& MELLO-SILVA, R. 2008. Levantamento florístico no cerrado de Pedregulho, SP, Brasil. Acta Bot. Bras. 22(1):187-202. http://dx.doi. org/10.1590/S0102-33062008000100019

SCARAMUZZA, C.A.M. 2006. Flora e ecologia dos campos de Itararé, São Paulo, Brasil. Tese de Doutorado, Universidade de São Paulo, São Paulo.

SILBERBAUER-GOTTSBERGER, L, MORAWETZ,W.\& GOTTSBERGER, G. 1977. Frost damage of cerrado plants in Botucatu, Brazil, as related to the geographical distribution of the species. Biotropica 9:253-261. http:// dx.doi.org/10.2307/2388143 
SILVA, F.A.M., ASSAD, E.D. \& EVANGELISTA, B.A. 2008. Caracterização climática do Bioma cerrado. In: cerrado: ecologia e flora (S.M. Sano, S.P. Almeida \& J.F. Ribeiro, orgs). Embrapa cerrados, Brasília, p.151-212.

SIQUEIRA, M.F. \& DURIGAN, G. 2007. Modelagem da distribuição geográfica de espécies lenhosas de cerrado no Estado de São Paulo Rev. Bras. Bot. 30(2):233-243.

SOUZA, V.C. \& LORENZI, H. 2008. Botânica sistemática: guia ilustrado para a identificação das famílias de Fanerógamas nativas e exóticas no Brasil, baseado em APG II. 2. ed. Instituto Plantarum, Nova Odessa.

SOUZA, V.C., MAMEDE, M.C.H., CORDEIRO, I., PRADO, J., BARROS, F., WANDERLEY, M.G.L., KAGEYAMA, P.Y., CECCANTINI, G. \& RANDO, J.G. 2007. Critérios utilizados na elaboração da Lista Oficial de Espécies da Flora Ameaçada de Extinção no Estado de São Paulo. In Livro vermelho das espécies vegetais ameaçadas do estado de São Paulo (M.C.H. Mamede, V.C. Souza, J. Prado, F. Barros, M.G.L. Wanderley \& J.G. Rando, orgs.). Instituto de Botânica, São Paulo, p.15-20.

SPECIES LINK. http://www.splink.cria.org.br (último acesso em 12/11/2010).
STOCKWELL, D.R.B. \& PETERSON, A.T. 2002. Effects of sample size on accuracy of species distribution models. Ecol. Model. 148:1-13. http:// dx.doi.org/10.1016/S0304-3800(01)00388-X

STRAUBE, F.C. 1998. O cerrado no Paraná: ocorrência original e atual e subsídios para sua conservação. Instituto Ambiental do Paraná, Curitiba. Cadernos de Biodiversidade.

TANNUS, J.L.S. \& ASSIS, M.A.A. 2004. Composição de espécies vasculares de campo sujo e campo úmido em área de cerrado, Itirapina - SP, Brasil. Rev. Bras. Bot. 27:489-509. http://dx.doi.org/10.1590/S010084042004000300009

VELOSO, H.P., RANGEL-FILHO, A.L.R. \& LIMA, J.C.A. 1991. Classificação da Vegetação Brasileira, adaptada a um sistema universal. IBGE, Rio de Janeiro.

WEISER, V.L. \& GODOY, S.A.P. 2001. Florística em um hectare de cerrado stricto sensu na ARIE - cerrado Pé-de-Gigante, Santa Rita do Passa Quatro, SP. Acta Bot. Bras. 15(2):201-212.

Recebido em 29/09/2011

Versão reformulada recebida em 31/03/2012

Publicado em 10/05/2012 